\title{
Cyclization and Cycloaddition Reactions of Cyclopropyl Carbonyls and Imines
}

\author{
Filippo De Simone and Jérôme Waser* \\ Laboratory of Catalysis and Organic Synthesis, Ecole Polytechnique Fédérale de Lausanne, EPFL SB ISIC LCSO, BCH 4306, 1015 \\ Lausanne, Switzerland. \\ Fax: +41216939700. \\ E-mail: jerome.waser@epfl.ch. \\ Received: The date will be inserted once the manuscript is accepted.
}

\begin{abstract}
Activated cyclopropanes, such as vinyl and carbonyl cyclopropanes, are useful building blocks in organic chemistry due to their exceptional reactivity. This review focuses on the use of cyclopropyl carbonyls and imines in cyclization and cycloaddition reactions for the synthesis of cyclic compounds. Cycloisomerization and other cyclization reactions are treated first, followed by formal cycloaddition reactions and applications in total synthesis. For each class of reactions, key pioneering works are shortly presented and emphasis is then set on recent results. Indeed, the utility of activated cyclopropanes in organic synthesis have been significantly increased in the last years by combining modern catalytic methods with the well-established reactivity of these building blocks. Together with progress in the synthesis of the cyclopropanes, these new methods allowed a better control over the diastereoselectivity and enantioselectivity of the reactions as well as their use for the synthesis of complex natural products.
\end{abstract}

1 Introduction and Scope of the Review

2 Cyclization Reactions

2.1 Nucleophile Attached to the Carbonyl

2.2 Nucleophile Attached to the Cyclopropane

3 Cyclization Reactions Involving Incorporation of Exogenous $\operatorname{Atom}(\mathrm{s})$

4 Formal [3+2] Cycloaddition Reactions

4.1 [3+2] Cycloaddition Reactions Cyclization with Olefins

$4.2[3+2]$ Cycloaddition Reactions Cyclization with Aldehydes and Ketones

4.3 [3+2] Cycloaddition Reactions Cyclization with Imines and Nitriles

4.4 Other [3+2] Cycloaddition Reactions Cyclization

5 Other Cycloaddition Reactions

$5.1[3+3]$ Cycloaddition Reactions

5.2 Other Cycloaddition Reactions

6 Applications in Total Synthesis

7 Conclusions

Key words: activated cyclopropanes, cyclizations, cycloadditions, isomerizations, stereoselective synthesis.

\section{Introduction and Scope of the Review.}

Small rings, especially cyclopropanes, occupy a privileged position in organic chemistry. ${ }^{1}$ The rigidity of the cyclopropyl group makes it an excellent scaffold for medicinal chemistry. ${ }^{1 \mathrm{c}}$ The ring strain energy confers an exceptional reactivity to the three-membered ring, which has been best described using the Walsh orbitals. ${ }^{2}$ Indeed, a partial $\pi$ character is observed, which can be used to explain several unique properties of cyclopropanes, such as carbocation stabilization, addition reactions and rearrangements. ${ }^{1}$

Despite its ring strain, cyclopropanes are usually chemically relatively inert, unless further activating groups are introduced on the ring. Especially, vinyl and carbonyl substituents have been traditionally used to enhance the reactivity of cyclopropanes. ${ }^{1}$ Recently, more reactive derivatives like alkylidene cyclopropanes and cyclopropenes have also been extensively examined. ${ }^{3}$ The importance of vinyl cyclopropanes have been largely demonstrated in rearrangement reactions, such as the vinylcyclopropyl to cyclopentene and the divinylcyclopropyl rearrangements. ${ }^{4}$ Furthermore, their use in metalcatalyzed cycloaddition reactions, for example [5+2] cycloadditions ${ }^{5}$ has been intensively investigated. In all these processes, the ring-opening reactions of the threemembered ring is used to generate larger ring-systems, especially 5 and 7- membered rings, which are not so easily accessed via other methods. The use of carbonyl cyclopropanes is even older and their potential to generate dissonant functional groups relationship via "homoconjugate" additions has been discovered already in 1895 by Perkin. ${ }^{6}$ Since then, opening cyclopropyl carbonyls has become a routine reaction and has been extensively used in organic synthesis. In contrast, the generation of new ring systems via the ring-opening step has been less extensively studied than in the case of vinyl cyclopropanes. Despite promising pioneering works mostly in the seventies by the group of Stork, ${ }^{7}$ Danishefsky $^{8}$ and Corey ${ }^{9}$ among others on intramolecular cyclization reactions of activated cyclopropanes, progress in the field has been slow. A notable exception was the introduction of more reactive donor-acceptor cyclopropanes, especially by the groups of Wenkert ${ }^{10}$ and Reissig. ${ }^{11}$ Nevertheless, it is only very recently that the full potential of carbonyl cyclopropanes has been fully realized, especially as exceptional building blocks for the construction of ring systems in catalytic reactions. This progress has also become possible due to important advances in the synthesis of cyclopropanes, including asymmetric methods. ${ }^{12}$

The goal of this review is to highlight the high potential of carbonyl cyclopropanes in cyclization and cycloaddition reactions. Although this particular topic has never been reviewed specifically, several important applications of activated cyclopropanes have appeared in other works covering the special reactivity of donor-acceptor cyclopropanes, ${ }^{13}$ the reactivity of cyclopropanes in the presence of transition metals, ${ }^{14}$ the activation of cyclopropanes using silyl groups ${ }^{15}$ and intramolecular addition reactions. ${ }^{16}$ These previously covered topics will be treated only shortly when necessary to gain a complete picture of the reactivity of carbonyl cyclopropanes, but the main focus will be on new recent progress, which has not yet been described extensively in the secondary liter- 
ature. The review will be focused on reactions where the carbonyl plays the main role in activation and processes where other functional groups are controlling the reactivity (for examples rearrangements involving vinyl cyclopropanes) will not be examined here.

In order to better classify cyclization and cycloaddition reactions involving cyclopropyl carbonyls, we have ordered them according to the number of exogenous atoms introduced during the process (Scheme 1). Cyclization reactions without introduction of exogenous atoms will be treated first (Ch. 2), followed by reactions where external atom(s) (usually a heteroatom nucleophile) are introduced (Ch. 3). Cycloaddition reactions with two atoms (Ch. 4) and larger fragments (Ch. 5) will be examined next. Many of these reactions are only formal cycloadditions, as they often proceed via stepwise mechanisms with no continuous overlap of orbitals in the transition state. For the sake of simplicity, however, we will just call them according to the total amount of atoms obtained in the product and consider the cyclopropane ring as a three atoms fragment. Finally, the review will cover recent applications of cyclopropyl carbonyls in the total synthesis of natural products (Ch. 6).

\section{Cyclization Reactions}

\subsection{Nucleophile Attached to the Carbonyl}

In the case of cyclization reaction of carbonyl cyclopropanes, the simplest case is the attack of the carbonyl oxygen itself on the cyclopropane. This reaction is the equivalent of the vinylcyclopropane to cyclopentene rearrangement and is indeed one of the oldest known reactions of cyclopropyl carbonyls. ${ }^{17}$ It is especially facile in the case of donor activated cyclopropanes, for which a mild acid is usually enough to catalyze the rearrangement. ${ }^{10,18}$ The reaction becomes faster if the cyclopropane is further activated with two ester groups and become spontaneous if one of the esters is exchange by a ketone. Indeed, the metal-catalyzed cyclopropanation of electron-rich double bonds (i.e. vinyl ethers) with diazo ketoesters or diketones usually leads directly to the dihydrofuran product. The intermediacy of a cyclopropyl is still a matter of debate, and depending on the reaction conditions, the formation of dihydrofuran has been shown to be possible via a cyclopropane intermediate or via a direct pathway. ${ }^{19}$ In 1999, Davies and co-workers developed a more reliable alternative using silyl enol ethers $\mathbf{2}$ as the diazo reagents to obtain cyclopropanes $\mathbf{3}$ in good yields. Simple deprotection with TBAF induced smooth formation of dihydrofuran 4 (Scheme 2). ${ }^{20}$ Alternatively, a Corey-Chaykovsky cyclopropanation-isomerization sequence has also been reported. ${ }^{21}$

Recently, the isomerization event has been incorporated in more complex processes for the synthesis of heterocycles. ${ }^{22} \mathrm{Hu}$ and co-workers reported the synthesis of angular dihydrofuroquinoline $\mathbf{6}$ via a Friedel-Craftisomerization sequence (Scheme 3). ${ }^{22 \mathrm{a}} \mathrm{Liu}$ and coworkers developed a general access to linear furoquinoline derivatives 8 (Scheme 4). ${ }^{22 \mathrm{~b}}$ In this case, $\mathrm{SnCl}_{4-}$ mediated dihydrofuran formation was proposed to occur first, followed by electrophilic aromatic substitution and water elimination.

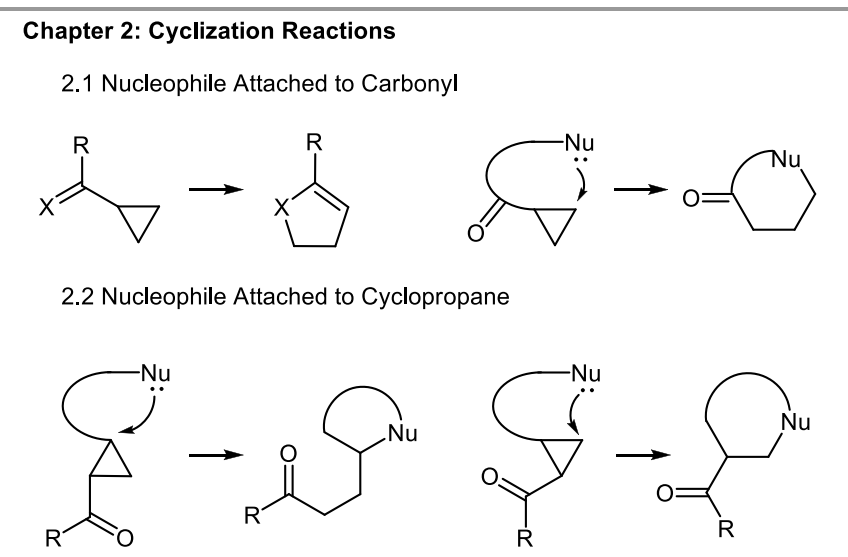

Chapter 3: Cyclization Reactions Involving Exogenous Atom(s)

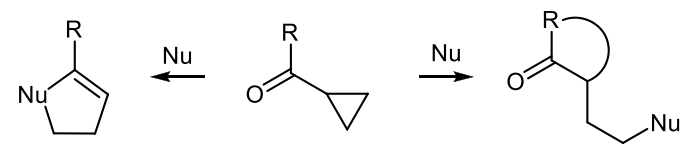

Chapter 4: Formal [3+2] Cycloaddition Reactions

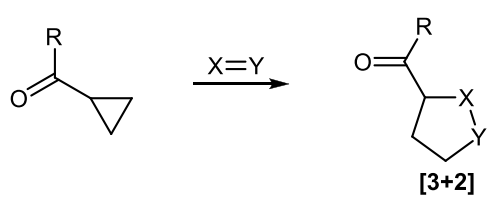

Chapter 5: Other Cycloaddition Reactions

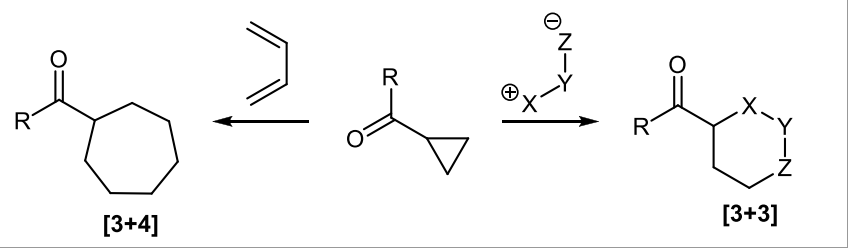

Scheme 1 Classification of cyclization and cycloaddition reactions involving cyclopropyl carbonyls.

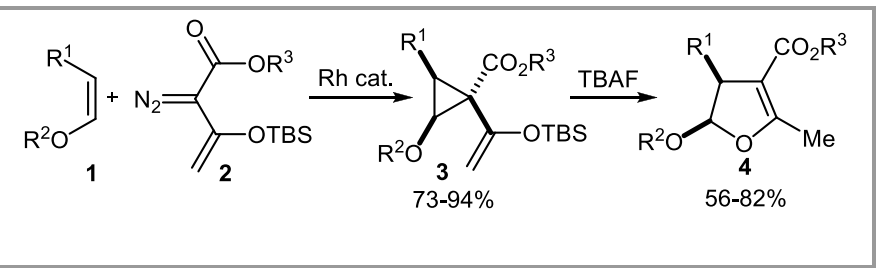

Scheme 2 Cyclopropanation-cycloisomerization sequence for the synthesis of dihydrofurans 4 .

The necessity of using multiply-activated cyclopropanes and/or harsh conditions is one of the major limitations for the use of carbonyl cyclopropanes in the synthesis of furan derivatives. Recent progress in this area includes the use of acyl silanes, ${ }^{23}$ the introduction of a silyl group to promote ring-opening via stabilization of carbocationic intermediate ${ }^{24}$ and the first reports on transition-metal mediated isomerization. ${ }^{25}$ Especially impressive is the 
Pd-catalyzed isomerization of alkylidene carbonyl cyclopropanes 9 developed by Ma and co-workers. ${ }^{25 a, b}$

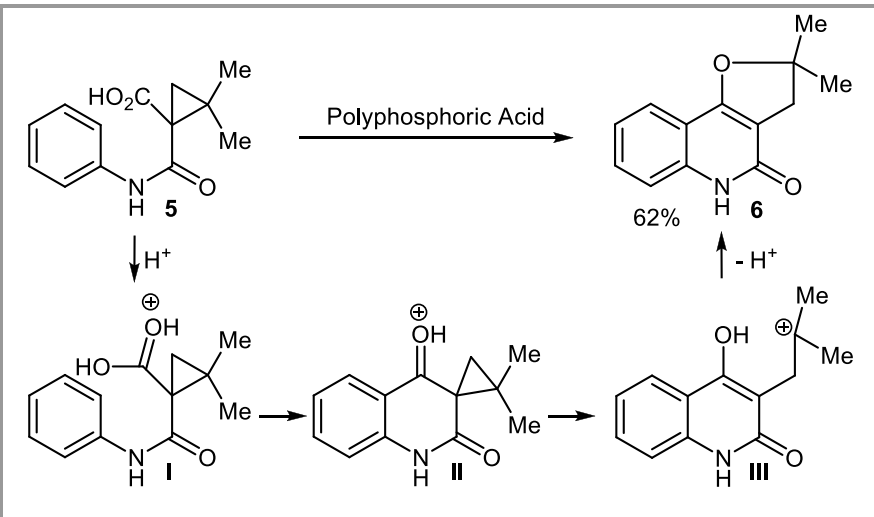

Scheme 3 Friedel-Craft-cycloisomerization sequence for the synthesis of angular dihydrofuroquinoline 6.

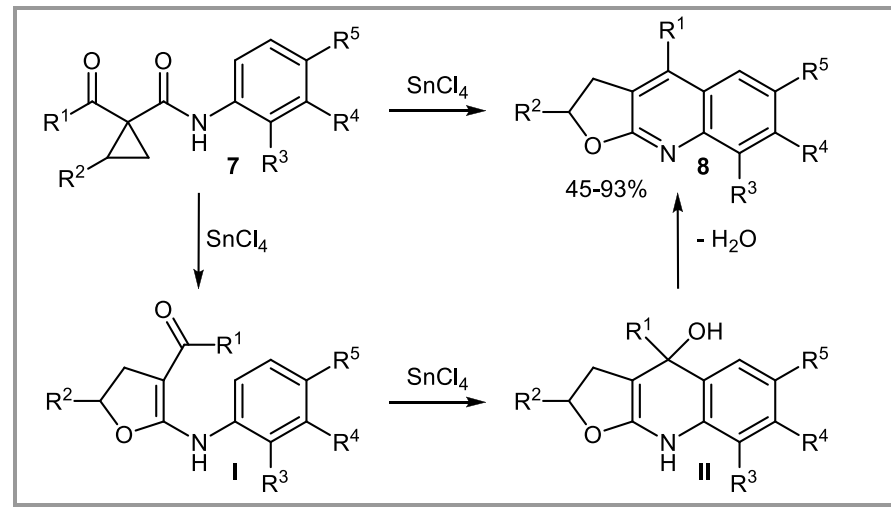

Scheme 4 Domino ring-opening/recyclization reactions for the synthesis of furoquinolines derivatives $\mathbf{8}$.

Depending on the reaction conditions, 4H-pyrans $\mathbf{1 0}$, 1,2,3-trisubstituted furans $\mathbf{1 1}$ or tetrasubstituted furans $\mathbf{1 2}$ can be obtained (Scheme 5). For the synthesis of $4 \mathrm{H}$ pyrans 10, a chloropalladation of the alkylidene was proposed as a first step (Scheme 6, A). $\beta$-Carbon elimination generated then a $\mathrm{Pd}$ enolate II. Intramolecular insertion of the alkene led to a Pd-dihydropyran intermediate III. Equilibration to IV followed by elimination of $\mathrm{PdCl}_{2}$ generated finally $4 \mathrm{H}$-pyrans $\mathbf{1 0}{ }^{26}$ Strikingly, furan product $\mathbf{1 1}$ was observed instead when the reaction was run in the presence of $\mathrm{NaI}$ (Scheme 6, B). In this case, the Pd catalyst was not required and a nucleophilic attack of iodide to induce ring-cleavage followed by intramolecular SN' attack of enolate $\mathbf{V}$ was proposed to rationalize the formation of the observed product $\mathbf{1 1}$ after isomerization of the initially formed exo-alkene VI. The use of iodide to open activated cyclopropanes has indeed be successful in several reactions of cyclopropyl carbonyls (vide infra). Finally, reaction in the presence of a $\operatorname{Pd}(0)$ catalyst proceeds probably via oxidative addition on the cyclopropane followed by intramolecular attack of enolate VIII on the Pd-allyl moiety to give the observed tetrasubstituted furan $\mathbf{1 2}$ after double bond isomerization (Scheme 6, C).

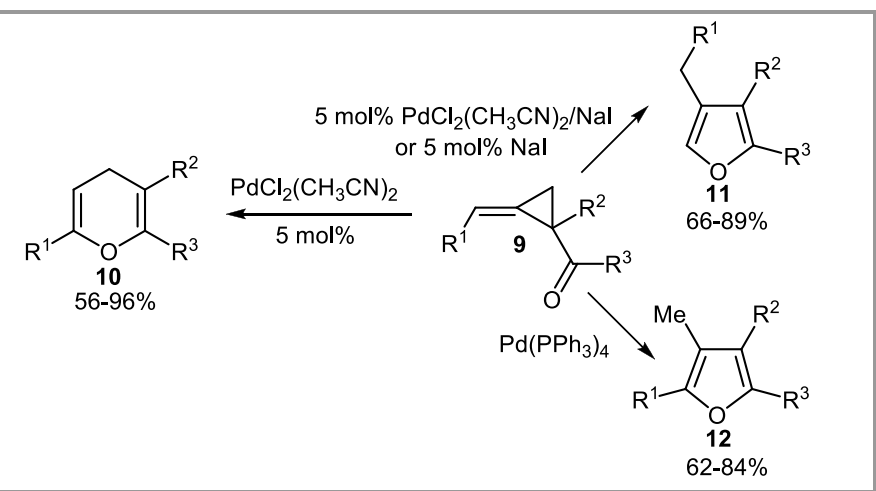

Scheme 5 Cycloisomerization of alkylidene carbonyl cyclopropanes 9.

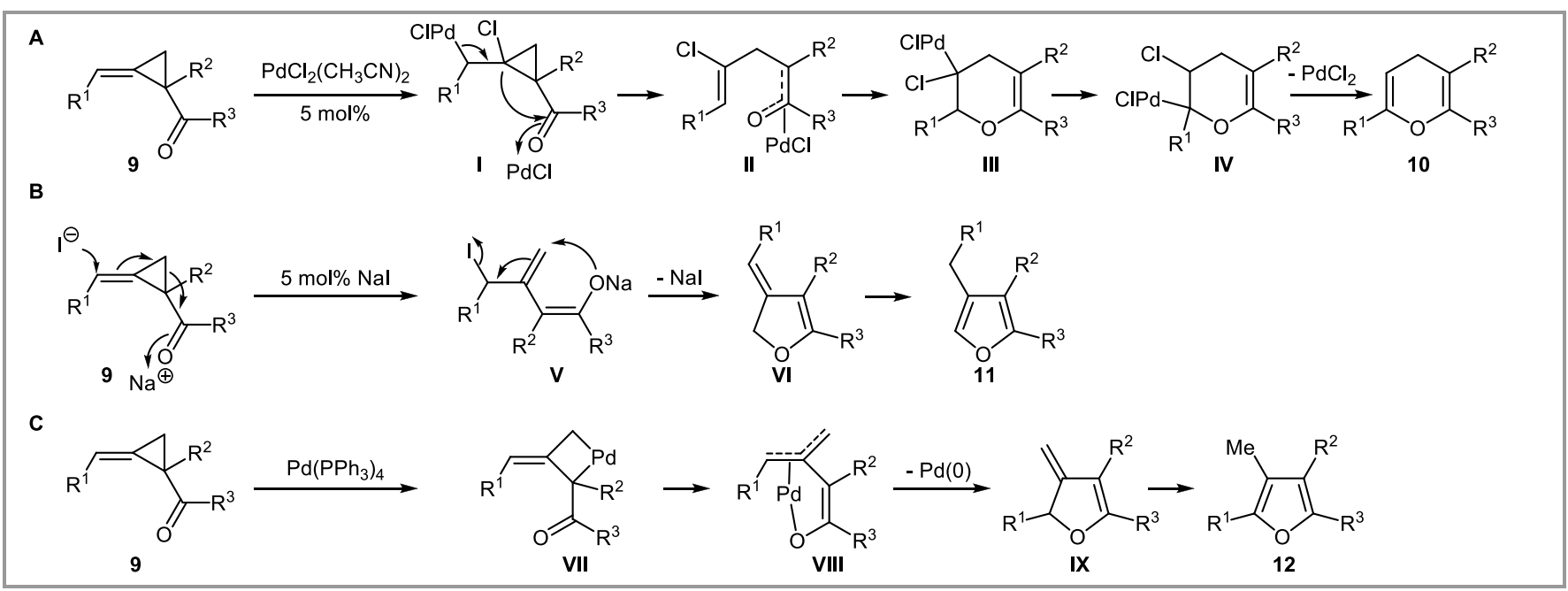

Scheme 6 Proposed mechanism for the cycloisomerization reactions of alkylidene carbonyl cyclopropanes 9.

In 2006, Bowman and Johnson reported that vinyl diketone cyclopropanes could be isomerized to the corresponding dihydrofuran using a $\mathrm{Ni}(0)$ catalyst. ${ }^{25 \mathrm{c}}$ The possibility to form a stabilized Ni-allyl intermediate upon ring-opening allowed to use very mild conditions. Most importantly, it was shown that the stereochemical integrity of cyclopropane $\mathbf{1 3}$ was completely conserved during the cycloisomerization reaction (Equation 1). 


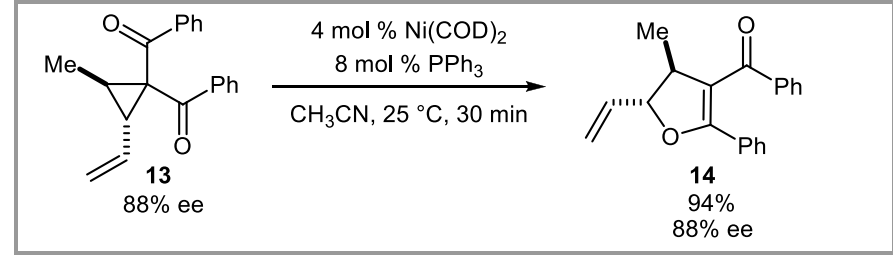

Equation 1

The cycloisomerization of carbonyl cyclopropanes is not limited to the formation of furan derivatives. Indeed, one of the oldest reports on such reactions by Cloke described the related isomerization of cyclopropyl imines to pyrrolines. ${ }^{27}$ This reaction was then extensively developed by Stevens and co-workers for the synthesis of alkaloid natural products. ${ }^{28}$ Purely thermal rearrangement appeared to be excessively slow, and a stepwise mechanism involving protonation of imines $\mathbf{1 5}$ and ringopening with a halide followed by cyclization to give pyrrolines $\mathbf{1 6}$ has been proposed (Scheme 7). ${ }^{29}$

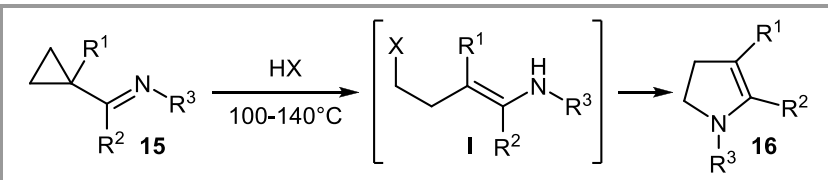

Scheme 7 Cloke-Stevens rearrangement of cyclopropyl imines $\mathbf{1 5}$.

The use of $\beta$-amino-cyclopropyl imines $\mathbf{1 8}$ has starting material was described by De Meijere and co-workers for the synthesis of pyrroles 19. ${ }^{30}$ In this case, cyclopropane stannane $\mathbf{1 7}$ was lithiated and added to a nitrile to give 18. Addition of acid led to formation of pyrroles 19 after amine elimination (Scheme 8).

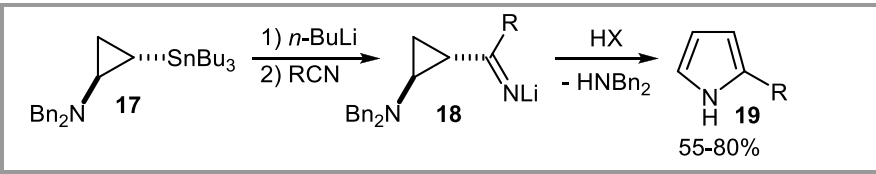

Scheme 8 Synthesis of pyrroles via $\beta$-amino-cyclopropyl imines 18.

Recently, the Cloke-like rearrangement of thioimidate has been reported by Kuduk and co-workers. ${ }^{31}$ Another useful extension of the methodology was introduced by Yang and Shi for the cyclization of cyclopropyl amides 20 to the corresponding $\gamma$-lactams 21 via an in situ formed bromo-imidate I (Scheme 9). ${ }^{32}$ Importantly, no further activating group beside the amide is needed on the cyclopropane.

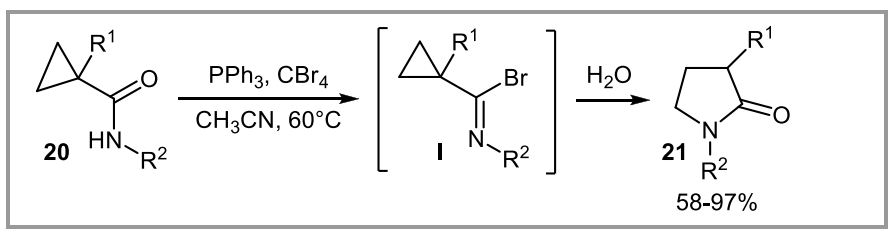

Scheme 9 Synthesis of $\gamma$-lactams 21 via imidate intermediate $\mathbf{I}$.
The ring-opening reaction of esters and acids to give lactones is also a well-established process, especially by the work of Wenkert. ${ }^{10}$ This reaction has proven very useful for the synthesis of fused $\gamma$-lactone/furan or pyran ring systems 23 (Equation 2). ${ }^{33}$ Wang and Du also reported the combination of the cycloisomerization reaction with an aldol condensation reaction in the case of activated vinyl-carboxylate cyclopropanes. ${ }^{34}$ Werz and co-workers used the iterative bidirectional cycloisomerization of donor-acceptor carboxaldehyde cyclopropanes for the synthesis of anti-oligoannelated THF structure $\mathbf{2 6}$ (Scheme 10). ${ }^{35}$ In this case, oxidation of alcohol 24 with IBX led directly to isomerization without isolation of the aldehyde.

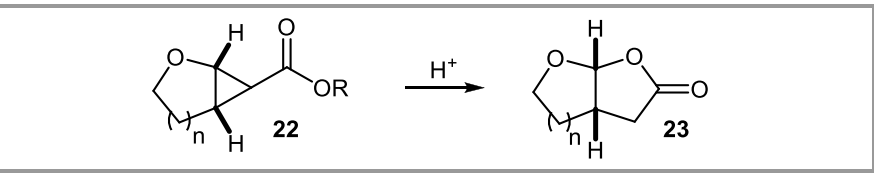

Equation 2

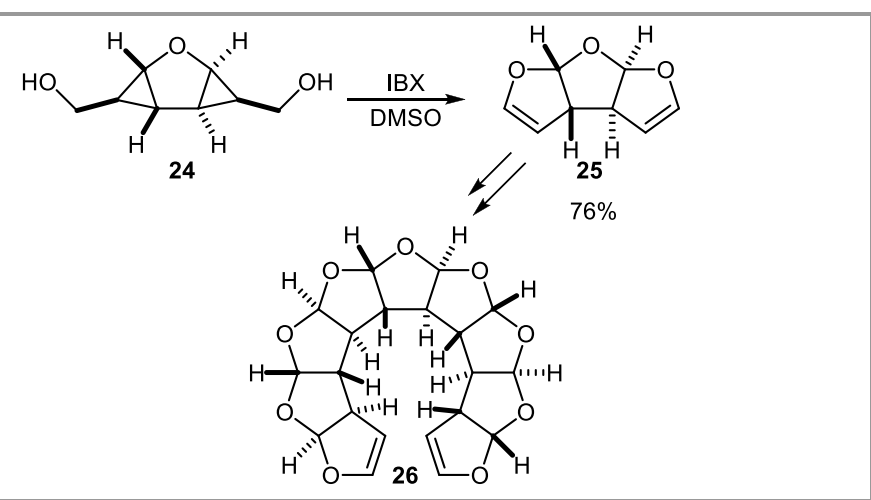

Scheme 10 Synthesis of anti-oligoannelated THF structure 26.

Recent efforts have focused on the development of similar procedures for the synthesis of $\gamma$-lactams starting from amides. Lautens and co-workers described the ringextension of methylene cyclopropyl amide 27 catalyzed by $\mathrm{MgI}_{2}$ (Scheme 11). ${ }^{36}$ The Lewis acidity of $\mathrm{Mg}$ is thought to activate cyclopropyl amide $\mathbf{2 7}$ for ringopening with iodide. The generated intermediate I can then cyclize to generate the observed unsaturated lactam 28 after proton transfer. If an electrophile, for example an aldehyde or a tosyl imine, is added, product $\mathbf{2 9}$ resulting from reaction of the $\gamma$ position of the conjugated enolate is observed. This reactivity towards electrophiles is highly dependent on the substitution on the amide, as for tertiary amides a formal [3+2] cycloaddition is observed (vide infra). The reaction was later extended to substituted alkylidene cyclopropyl amides. ${ }^{36 \mathrm{~b}}$ In this case, lactams with an exo double bond were favored. 


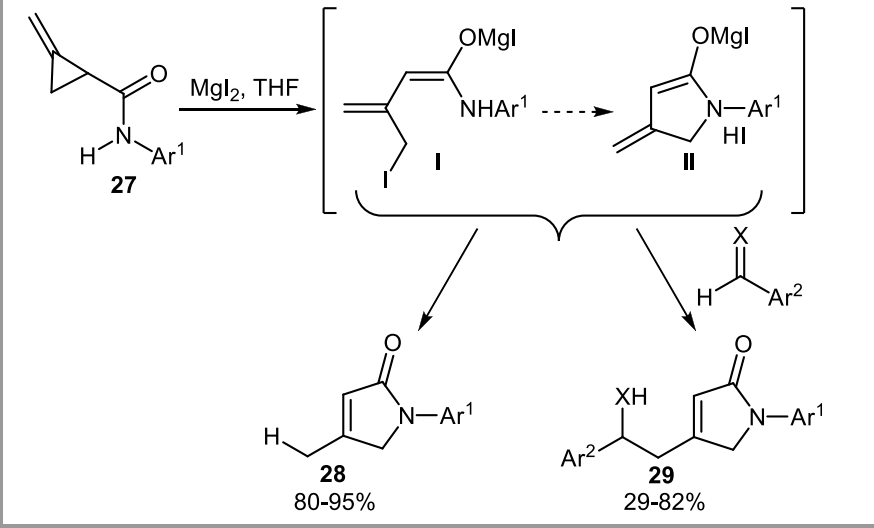

Scheme 11 Synthesis of unsaturated $\gamma$-lactams 28 and 29 from methylene cyclopropyl amides 27.

In 2007, Lautens and co-workers reported the first cycloisomerization of methylene cyclopropyl hydrazones 30 (Scheme 12). ${ }^{37}$ Two different azadiene products 31 and 32 could be obtained selectively depending on the reaction conditions. In this case, an intramolecular attack of the hydrazone on the cyclopropane without involvement of an allyl halide intermediate was proposed. Further investigations are still needed to rationalize the exquisite selectivity observed depending on reaction conditions.

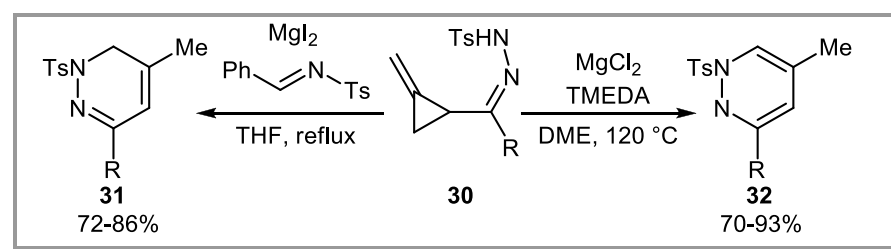

Scheme 12 Synthesis of diazadienes $\mathbf{3 1}$ and $\mathbf{3 2}$ from methylene cyclopropyl hydrazones $\mathbf{3 0}$.

The cyclization reaction of cyclopropyl imides is another alternative to obtain pyrrolidone products. ${ }^{38}$ In 2008 , Shibasaki developed a ring-opening-aldol-cyclization sequence for the diastereoselective synthesis of $\gamma$ lactams 34 starting from cyclopropyl imides 33 (Equation 3). ${ }^{38 \mathrm{~b}}$ The reaction was initiated by electrophilic activation with a Sc Lewis acid, followed by homo-conjugate addition of iodide to form an enolate intermediate $\mathbf{I}$ (Scheme 13). A diastereoselective aldol reaction via a chair transition state was proposed to account for the observed diastereoselectivity. Finally, proton transfer and cyclization to form lactam $\mathbf{3 4}$ closed the catalytic cycle.

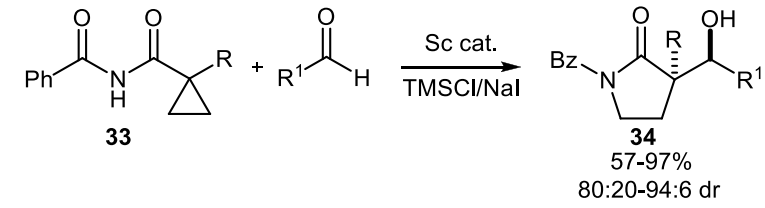

Equation 3

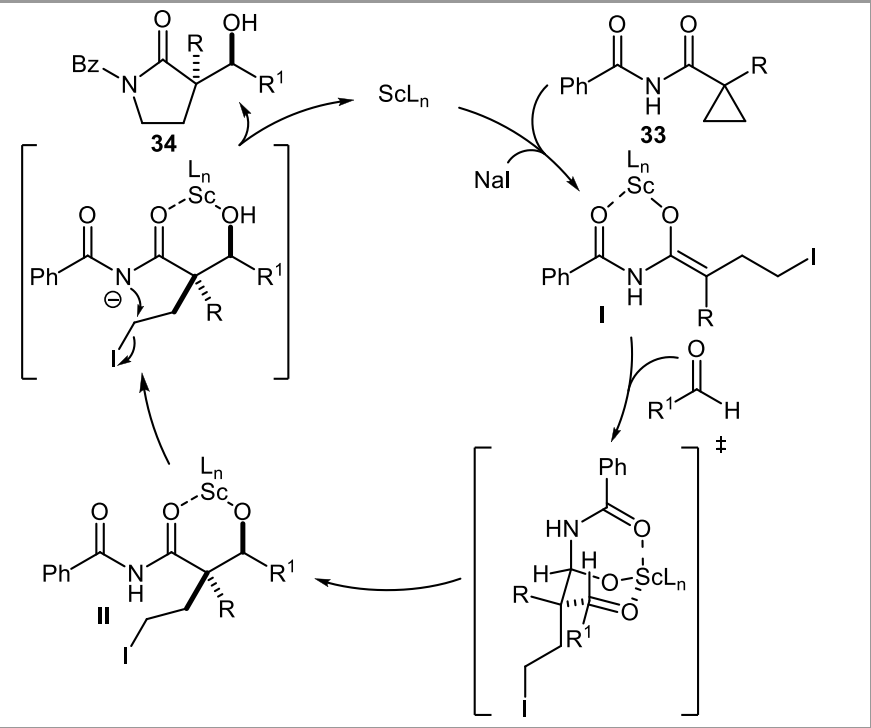

Scheme 13 Mechanism for the ring-opening-aldol-cyclization sequence.

An alternative strategy for the synthesis of pyrrolines starting from cyclopropanes makes use of the imines derived from $\beta$-amino-cyclopropane carboxylates. ${ }^{39}$ Finally, another approach starting from $\beta$-azidocyclopropane dicarboxylates for the synthesis of lactams has been reported by De Kimpe and co-workers. ${ }^{40}$

A mechanistically new approach has been recently introduced for the N-heterocyclic carbene (NHC) cycloisomerization of keton-carboxaldehyde cyclopropane to 3,4dihydropyrones. ${ }^{41}$ Based on pioneering work about the redox opening of formyl cyclopropanes, ${ }^{42} \mathrm{Du}$ and Wang reported a single example of this reaction in $2008 .{ }^{41 a}$ You and co-workers then demonstrated the generality of the reaction for the generation of dihydropyrone 37 (Equation 4). ${ }^{41 \mathrm{~b}}$ Mechanistically, this reaction is thought to proceed via addition of the NHC $\mathbf{3 6}$ on aldehyde $\mathbf{3 5}$, followed by proton-tranfer and ring opening to give an enol intermediate III (Scheme 14). After enol-ketone tautomerization, the attack of the enolate oxygen leads to formation of pyrone $\mathbf{3 7}$ and release of the catalyst $\mathbf{3 6}$.

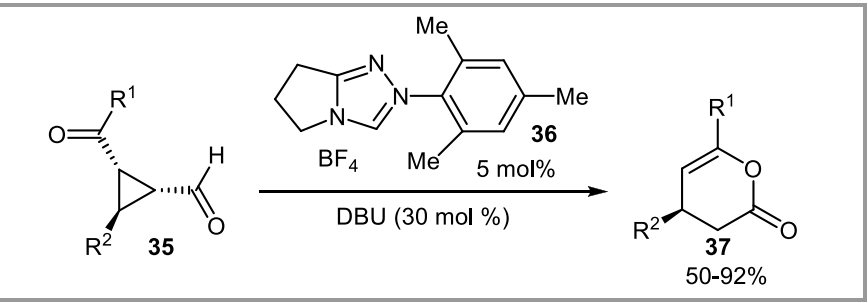

Equation 4 


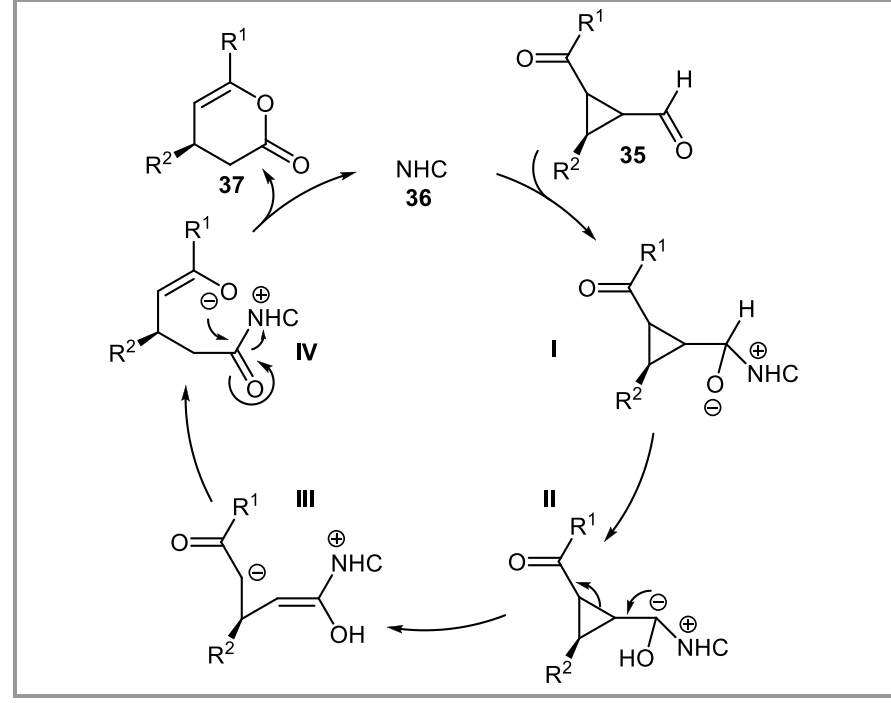

Scheme 14 Mechanism for the NHC mediated redox cycloisomerization.

A different set of reactions is possible when the nucleophile is not directly part of the carbonyl functionality. This kind of reactions is mostly limited to electron-rich double bonds and aromatic groups. The first example of such reaction was introduced by Murphy and Wattanasin in 1980 for the synthesis of tetralones $\mathbf{3 9}$ from aryl cyclopropyl ketones 38 using excess $\mathrm{SnCl}_{4}$ (Scheme 15). ${ }^{43}$ This reaction corresponds formally to a homologous variation of the well-known Nazarov cyclization. ${ }^{44}$ In contrast to the concerted Nazarov reaction, a stepwise process via carbocationic intermediates I and II has been proposed. In accordance with this mechanism, the cyclization was successful only if the cyclopropane was substituted with an electron-rich aromatic group. Furthermore, only electron-rich benzene rings were used on the ketone.

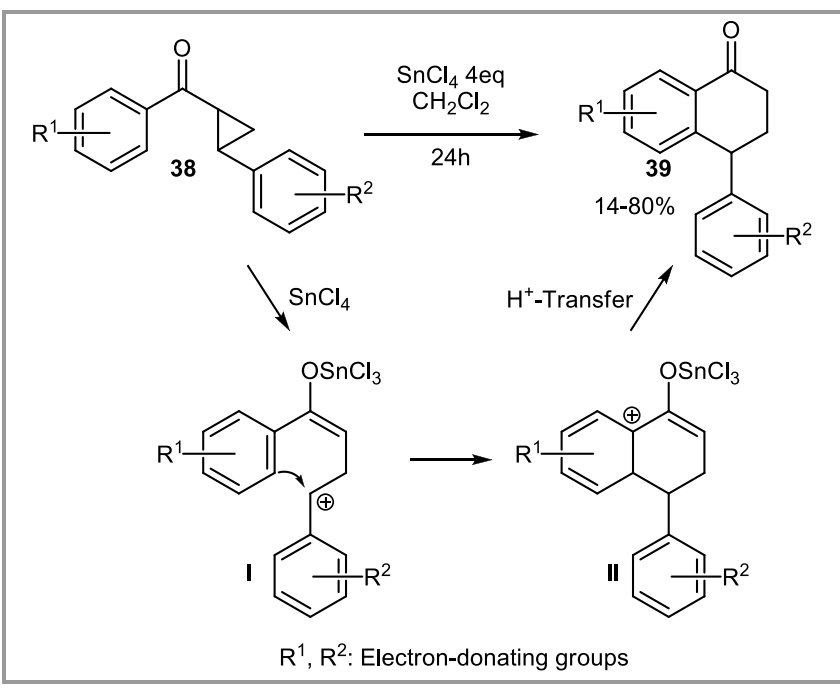

Scheme 15 Formal homo-Nazarov reaction for the synthesis of tetralone derivatives $\mathbf{3 9}$.

In 2005, Otto and co-workers showed that ketones bearing a furan or a thiophene substituent were also good substrate for the cyclization reaction. ${ }^{45}$ In 2008, Yadav and Kumar greatly expanded the scope of the reaction by using a bulky silyl group to stabilize the carbocationic intermediate (Equation 5). ${ }^{46}$ Several heterocyclic ketones 40 could be cyclized in good yield using 4 equivalents $\mathrm{SnCl}_{4}$ at $80{ }^{\circ} \mathrm{C}$. Importantly, the first example of oxygen substituent as donor group was also reported in this work (40c in Equation 5).

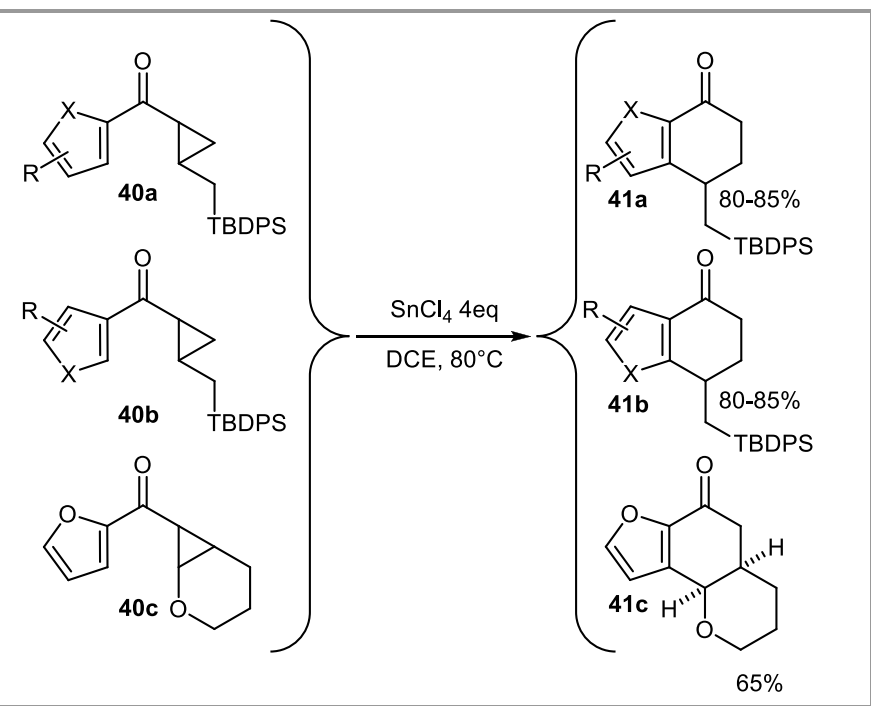

Equation 5

The cyclization of the related vinyl cyclopropyl ketones has been much less examined. In 1986, Tsuge and coworkers described the cyclization of several vinylcyclopropyl ketones in the presence of large excess of polyphosphoric acid, but a mixture of different products were usually obtained under these conditions. ${ }^{47}$ In 2009 , Waser and co-workers introduced cross-polarized substrates $\mathbf{4 2}$ for the first time in the homo-Nazarov reaction. ${ }^{48}$ Similar cross-polarized substrates were used successfully in the related Nazarov cyclization. ${ }^{49}$ This work resulted in the development of the first catalytic method for the formal homo-Nazarov cyclization (Equation 6). The mild reaction conditions $\left(20 \mathrm{~mol} \% \mathrm{TsOH}, \mathrm{CH}_{3} \mathrm{CN}\right.$, RT) were essential to prevent extensive polymerization of the sensitive substrates. The polarizing heteroatom $\alpha$ to the ketone could also be replaced by a silyl group as in $\mathbf{4 4}$, in which case complete diastereoselectivity was observed in the formation of the new chiral center and the double bond was formed only at the position of the silyl group to give 45 (Equation 7). Current limitation of this methodology is the necessity of having an electron-rich aromatic substituent on the cyclopropanes to promote the cyclization.

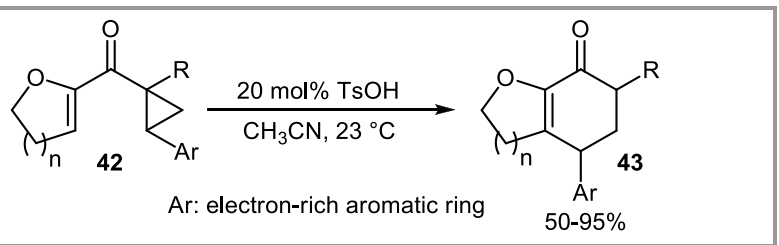

Equation 6 


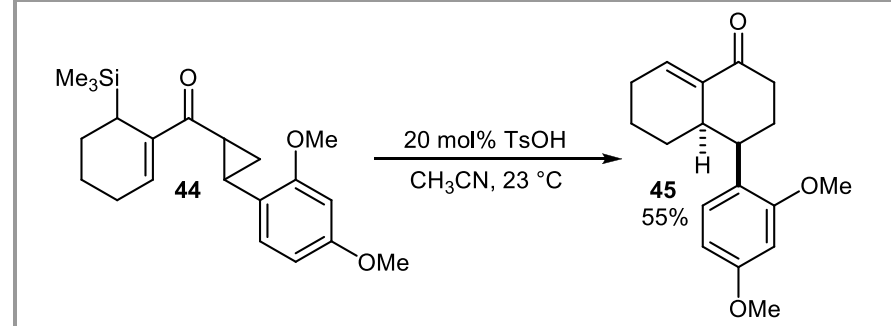

Equation 7

In another type of cyclization process, Junjappa and coworkers introduced ketenedithioacetal as a nucleophile to react with the carbocationic intermediate ${ }^{50}$ In this case, formation of the five-membered ring was observed. In the first works, the stabilized cations obtained after cyclization were just quenched with water, and either thioesters $\mathbf{4 7}$ or decarboxylated cyclopentanones $\mathbf{4 8}$ could be obtained depending on the reaction conditions (Equation 8). ${ }^{50 \mathrm{a}-\mathrm{c}}$ More recently, Junjappa and coworkers developed further cationic domino cyclization processes, involving electron-rich benzene rings or heterocycles (Scheme 16). ${ }^{50 \mathrm{~d}-\mathrm{j}}$

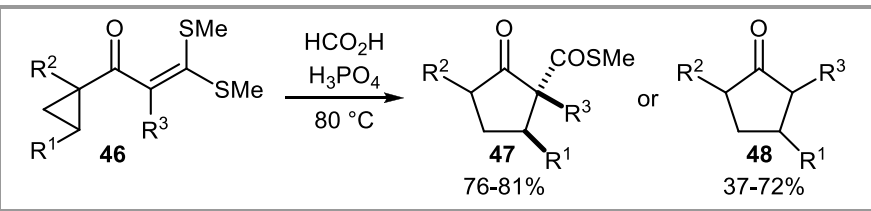

Equation 8

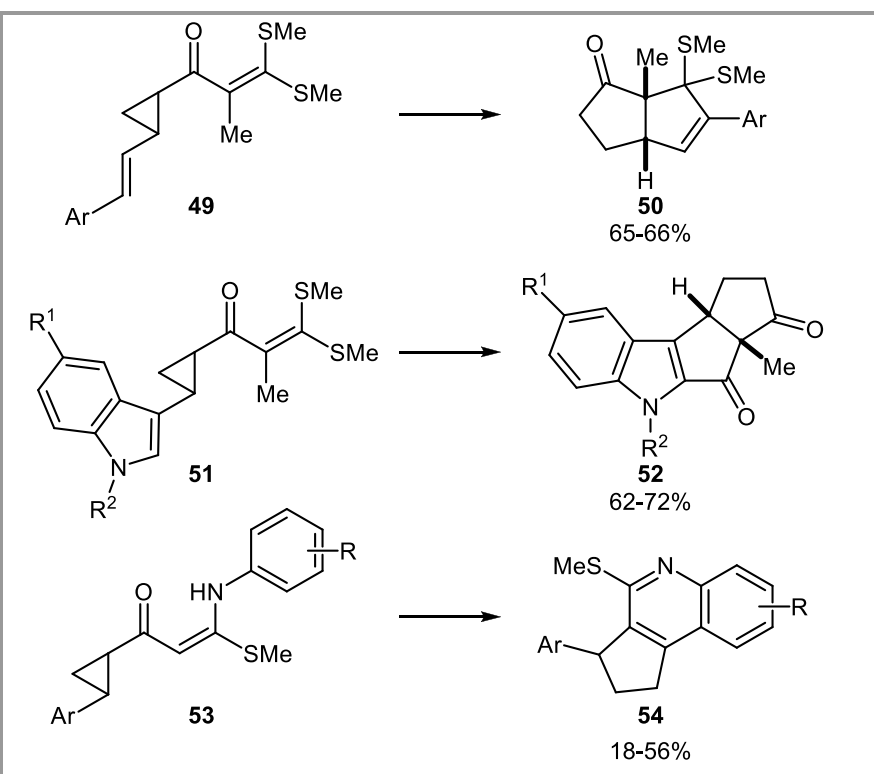

Scheme 16 Cationic domino reactions using ketenedithioacetals 49 and $\mathbf{5 1}$ with double bond ${ }^{50 \mathrm{e}}$ or indoles ${ }^{50 \mathrm{i}}$ as final nucleophiles and using keteneaminothioacetals $\mathbf{5 3}$ and aromatic group as final nucleophile. ${ }^{50 \mathrm{j}}$

\subsection{Nucleophile Attached to the Cyclopropane}

The intramolecular attack of nucleophiles attached on the cyclopropane ring of carbonyl cyclopropanes has been extensively examined in the groups of Stork ${ }^{7}$ and Danishefsky ${ }^{8}$ among others ${ }^{51}$ in the 60's and 70's. These methods have proven highly useful in the synthesis of natural products. As this work has been already reviewed, ${ }^{8 \mathrm{e}}$ only a few relevant examples are given in Scheme 17.

\section{Stork and Marx}

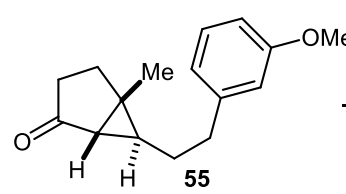

Danishefsky and Co-workers
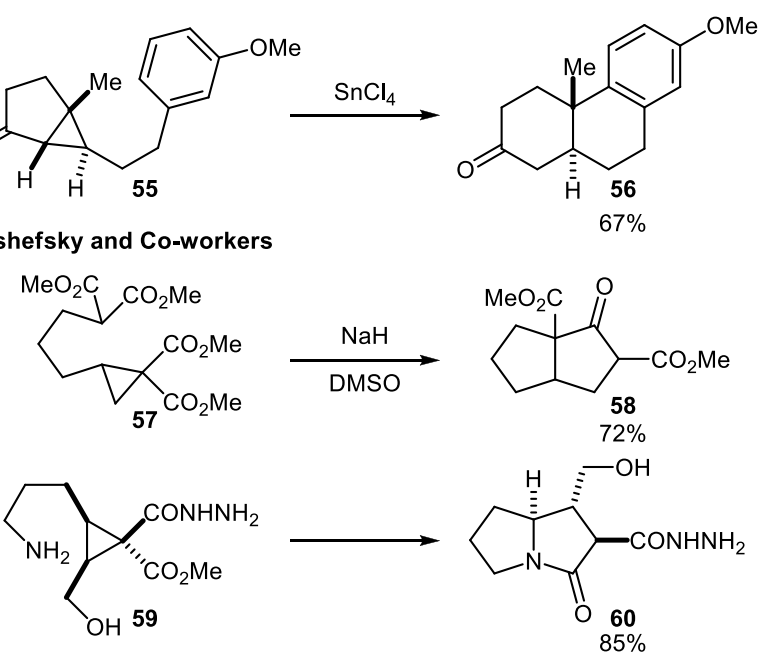

Scheme 17 Some typical examples of intramolecular cyclization of activated cyclopropanes developed in the groups of Stork ${ }^{7}$ and Danishefsky. ${ }^{8}$

Despite these early successes, similar intramolecular cyclization reactions have been less intensively used in the following years. Smith and co-workers developed one pot cyclopropanation-cyclization sequences. ${ }^{52}$ Reissig and co-workers described the intramolecular ring-opening of donor-acceptor cyclopropanes with alcohol nucleophiles. ${ }^{11 e, 11 \mathrm{f}}$ The use of a phenolate nucleophile was reported by Wood and co-workers in the context of model studies towards the synthesis of the original proposed structure of the diazonamides.$^{53} \mathrm{Bohm}$ and Reiser developed a two steps procedure for the synthesis of butyrolactone 63 starting from carboxaldehyde donoracceptor cyclopropane $\mathbf{6 1}$ (Scheme 18). ${ }^{54} \mathrm{~A}$ highly diastereoselective addition of nucleophiles to aldehyde $\mathbf{6 1}$ was followed by transesterification using Otera's catalyst, cyclopropane ring opening, lactonization and acetal formation. Importantly, the enantiopure donor-acceptor cyclopropanes needed for this methodology could be accessed easily in two steps (asymmetric cyclopropanation and ozonolysis) from furan derivatives.

In 2008, Wang and co-workers reported the Yb-catalyzed intramolecular addition of aromatic nucleophiles on alkylidinene cyclopropane dicarboxylates 64 (Equation 9). ${ }^{55}$ Activation with the $\mathrm{Yb}$ Lewis acid resulted in formation of a zwitterionic intermediate I followed by intramolecular attack to form the less strained ring systems 65. 


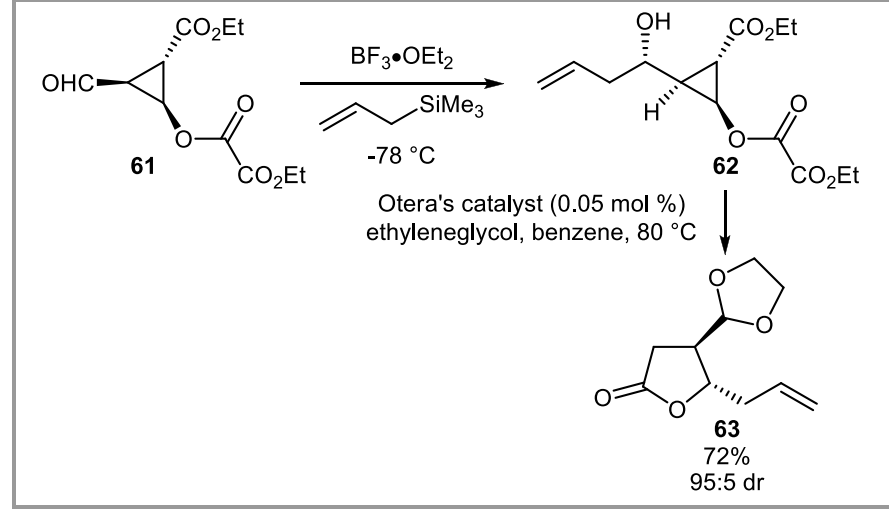

Scheme 18 Conversion of carboxaldehyde donor-acceptor cyclopropane $\mathbf{6 1}$ to butyrolactone $\mathbf{6 3}$.

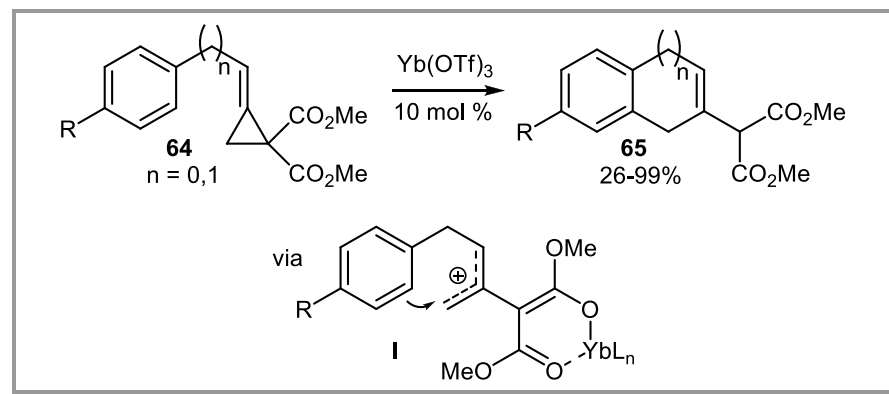

Equation 9

\section{Cyclization Reactions Involving incorporation of Exogenous Atom(s)}

An alternative to the intramolecular attack of a nucleophile onto an activated cyclopropane is an external attack of a heteroatom nucleophile, followed by cyclization (involving the introduced heteroatom or not, see Scheme 1). The simplest nucleophile, water, was used by Singh and Danishefsky for the efficient synthesis of trans-fused $\gamma$-lactone 67 (Equation 10) starting from cyclopropane $\mathbf{6 6}$ derived from Meldrum's acid. ${ }^{56}$

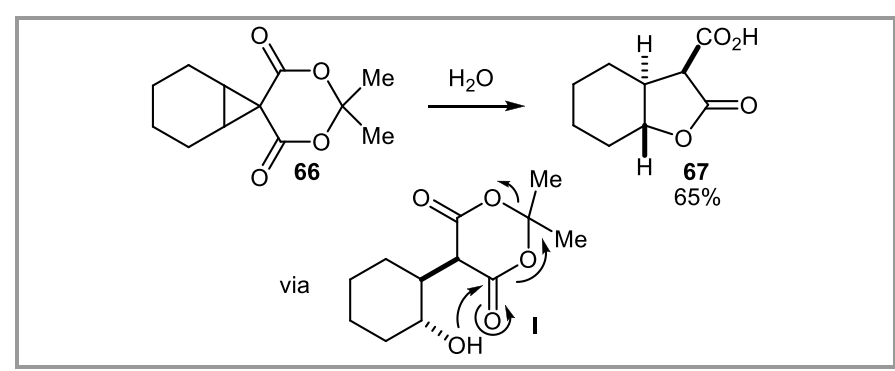

Equation 10

Shi and co-workers developed a water-mediated cyclopropane ring-opening-aldol condensations cascade for the synthesis of diverse heterocycles. ${ }^{57}$ For example, a ring-opening-aldol condensation-cyclization sequence allowed a new access towards spiroacetals 70 (Scheme 19). ${ }^{57 b, 57 \mathrm{c}}$ In situ reaction with allene esters led directly to the formation of aromatic products. ${ }^{57 \mathrm{~d}, 57 \mathrm{e}}$

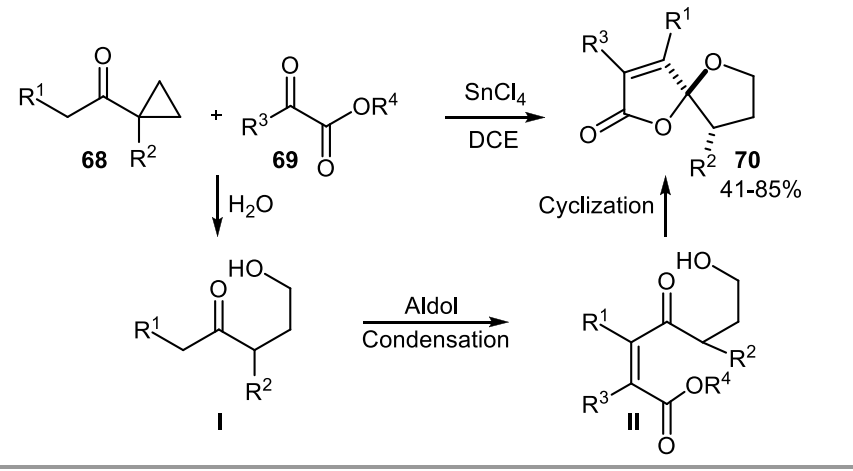

Scheme 19 The water addition-aldol condensation-cyclizationesterification sequence.

Examples of addition-cyclization of amine nucleophiles have also been reported. ${ }^{8 \mathrm{~d}, 58}$ Wurz and Charette reported the addition of primary amines to activated cyclopropanes $\mathbf{7 1}$ followed by oxidation for the synthesis of pyrrole heterocycles 72 (Equation 11).$^{59}$ Addition of primary amine to alkylidene cyclopropyl ketones $\mathbf{7 3}$ by $\mathrm{Ma}$ and co-workers allowed a redox neutral one step synthesis of pyrrole heterocycles 74 (Equation 12) ${ }^{60}$

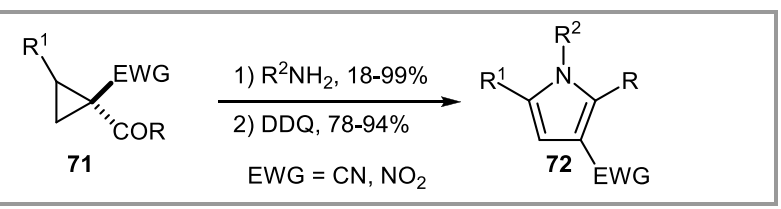

Equation 11

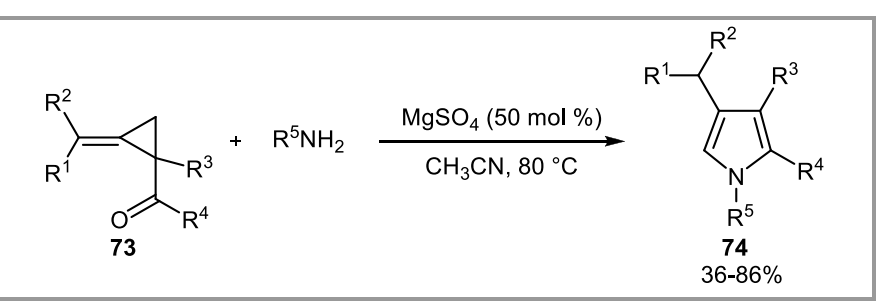

Equation 12

A different type of cyclization is observed for cyclopropyl dicarbonyls $\mathbf{7 5}$ in the presence of hydrazine or hydroxylamine salts (Scheme 20) ${ }^{61 \mathrm{a}-\mathrm{c}}$ In this case, condensation precedes ring opening by an external nucleophile and the carbon atoms of the cyclopropane are consequently not included in the formed pyrazole and isoxazole heterocycles 76. Based on the same principle, Langer and co-workers developed the reaction of 1,1diacylcyclopropanes with 1,3-bis-silyl enol ethers for the synthesis of highly substituted benzene rings. ${ }^{61 \mathrm{~d}-\mathrm{h}}$

In 2006, Zhang and Schmalz reported an interesting use of carbonyl cyclopropanes $\mathbf{7 7}$ for the synthesis of furans 78 via gold catalysis (Equation 13). ${ }^{62 a}$ Detailed calculations by Phillips and co-workers allowed a deeper insight in the reaction mechanism (Scheme 21). ${ }^{62 \mathrm{~b}}$ Activation of acetylene $\mathbf{7 7}$ with the gold catalyst leads to intramolecular attack of the ketone oxygen to form an oxonium ion II. The increased electrophilicity of the cyclopropane allows then an easy attack of an external nucleophile. 
Finally, proton transfer liberates the gold catalyst. In 2008, Huang and co-workers reported that a similar cyclization process was also possible using stoichiometric electrophiles, such as $\mathrm{I}_{2}$ or $\mathrm{PhSeBr}$, to activate the alkyne. ${ }^{63}$

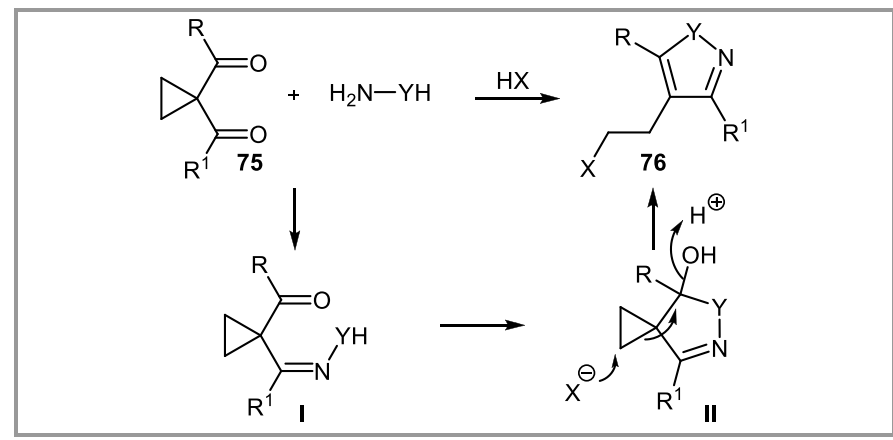

Scheme 20 Formation of heterocycles 76 from cyclopropane dicarbonyls $\mathbf{7 5}$ using hydrazine or hydroxylamine.

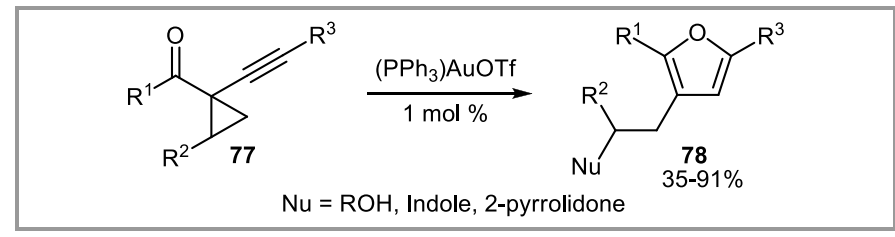

Equation 13

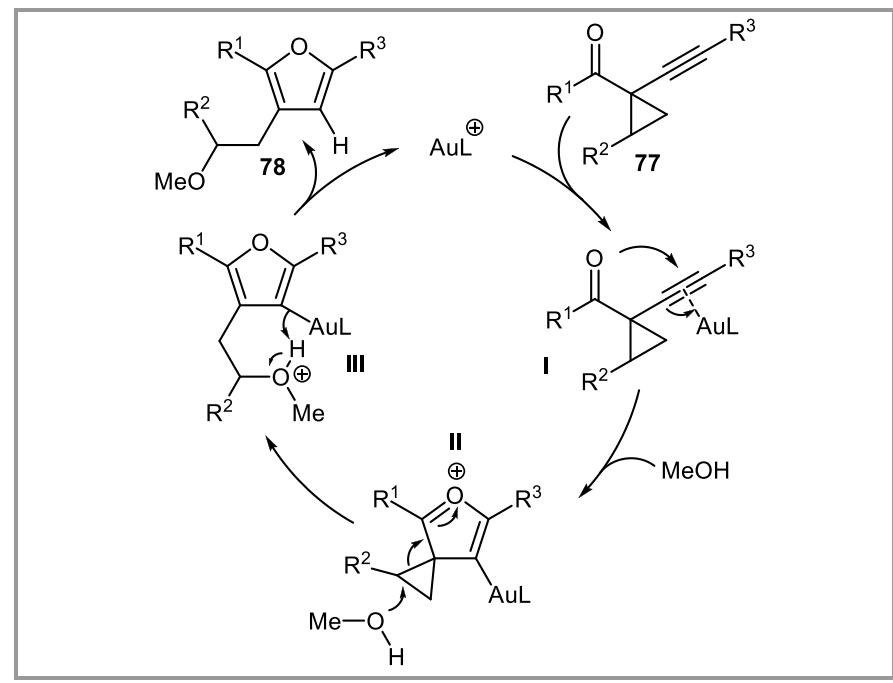

Scheme 21 Proposed mechanism for the gold catalyzed furan synthesis with methanol as nucleophile.

Finally, a mechanistic intriguing conversion of alkylidenecyclopropane carboxaldehydes $\mathbf{7 9}$ to the corresponding chlorocyclobutanes $\mathbf{8 1}$ has been reported by Huang and Miao (Scheme 22). ${ }^{64}$ This ring expansion reaction was proposed to proceed via acylation of the aldehyde, intramolecular attack of the cation by the double bond to form a bicyclobutanium ion II and ring opening with chloride.

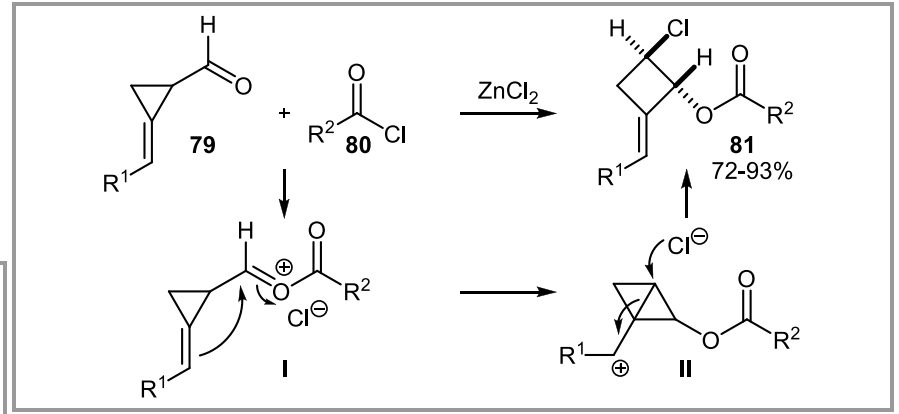

Scheme 22 Proposed mechanism for ring expansion of alkylidinene cyclopropane carboxaldehydes $\mathbf{7 9}$.

\section{Formal [3+2] Cycloaddition Reactions}

The heterolytic cleavage of one of the bonds of activated cyclopropanes results in the formation of a 1,3-dipole ideally suited for cycloaddition reactions. Especially formal $[3+2]$ cycloaddition reactions with olefins, carbonyls and imines have been highly successful for the synthesis of cyclopentane, furan and pyrrolidine derivatives respectively.

\section{1 [3+2] Cycloaddition Reactions with Olefins}

The 1,3-dipolar cycloaddition of activated cyclopropanes has been known for a long time (Scheme 23). ${ }^{9,65} \mathrm{~A}$ few selected early examples include the reactions of diverse activated cyclopropanes with electron-rich double bonds, such as enamines 82, ${ }^{65 a, b}$ enol ethers $\mathbf{8 5}^{65 \mathrm{c}}$ and ketene acetals $\mathbf{8 8}^{65 \mathrm{~d}}$ (Scheme 23, A-C), electron-poor double bonds $91^{65}$ (Scheme 23, D) and non-activated olefins $\mathbf{9 4}^{9}$ and $\mathbf{9 6}^{65 \mathrm{f}}$ (Scheme 23, E-F). 


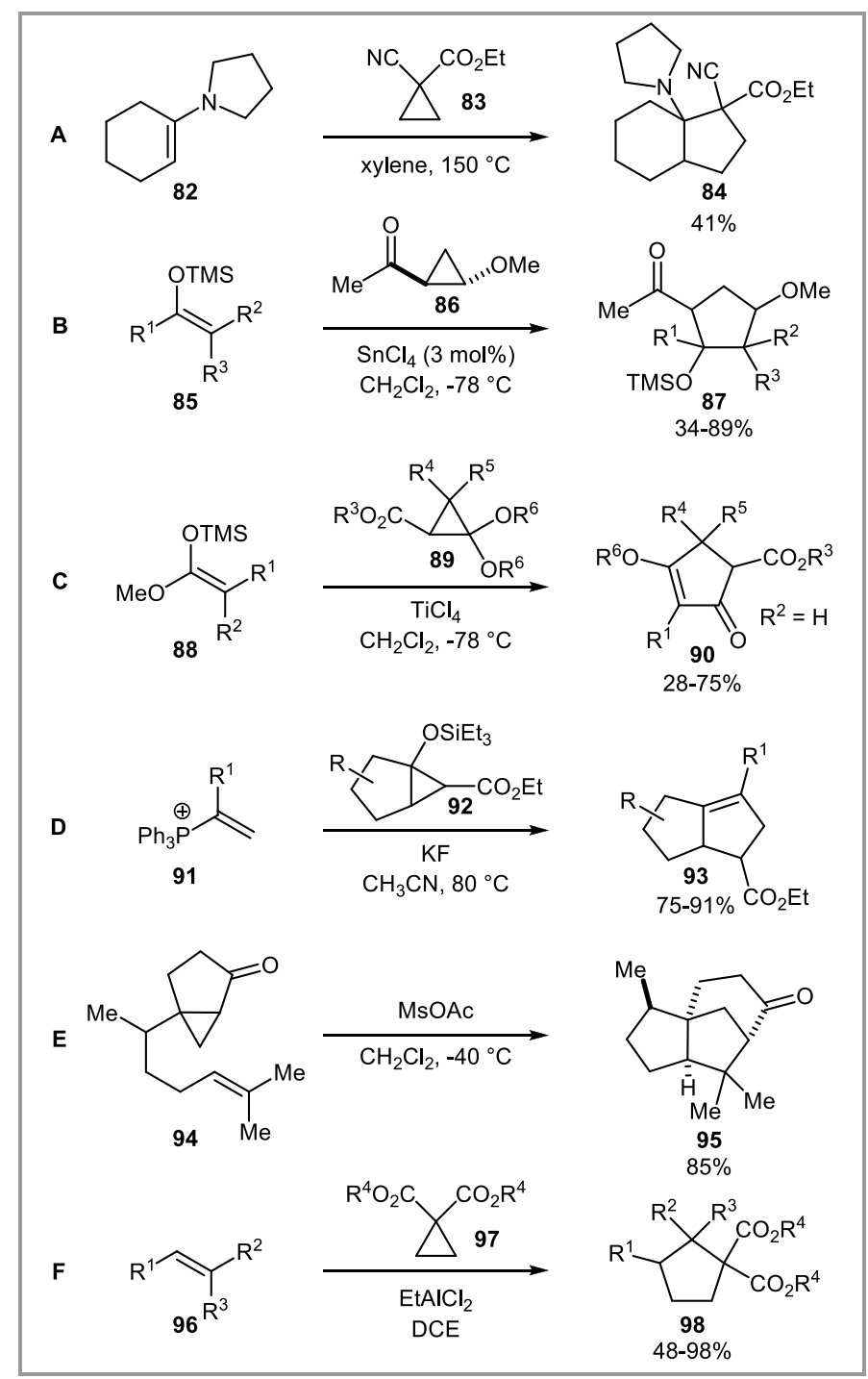

Scheme 23 Selected examples for early reports of cycloaddition reactions of activated cyclopropanes with olefins.

In view of the synthesis of natural products, the recent introduction of indoles as nucleophilic partners in [3+2] cycloaddition with activated cyclopropanes is particularly interesting. ${ }^{66}$ Kerr and co-workers reported that the result of the reaction of indole derivatives 99 with aryl substituted activated cyclopropanes $\mathbf{1 0 0}$ is highly dependent from the substitution pattern on 99 (Scheme 24). ${ }^{66 a-d}$ No cyclization was observed with an hydrogen at the 3 position of the indole, but the [3+2] addition product 102 was obtained in good yield in the other cases. If the 2 position of the indole was unsubstituted, cycloadduct 102 could be rearranged to the open form 103 upon heating. In 2006, Junjappa and co-workers observed that consistent formation of the [3+2] product was observed with all substitution pattern using $\mathrm{BF}_{3} \cdot \mathrm{OEt}_{2}$ in nitromethane. ${ }^{66 e}$ In 2007, Pagenkopf and co-workers reported the use of oxygen- substituted activated cyclopropanes 105 with TMSOTf as activator (Equation 14). ${ }^{67 a}$ This reaction was especially well-suited for the synthesis of tetracyclic indole derivatives 106. The observed diastereoselectivity was highly dependent on the cyclopropane used. In 2009, the use of donor-acceptor cyclopropanes was extended to [3+2] cycloaddition reactions with furan heterocycles by Budynina and coworkers. ${ }^{67 \mathrm{~b}}$

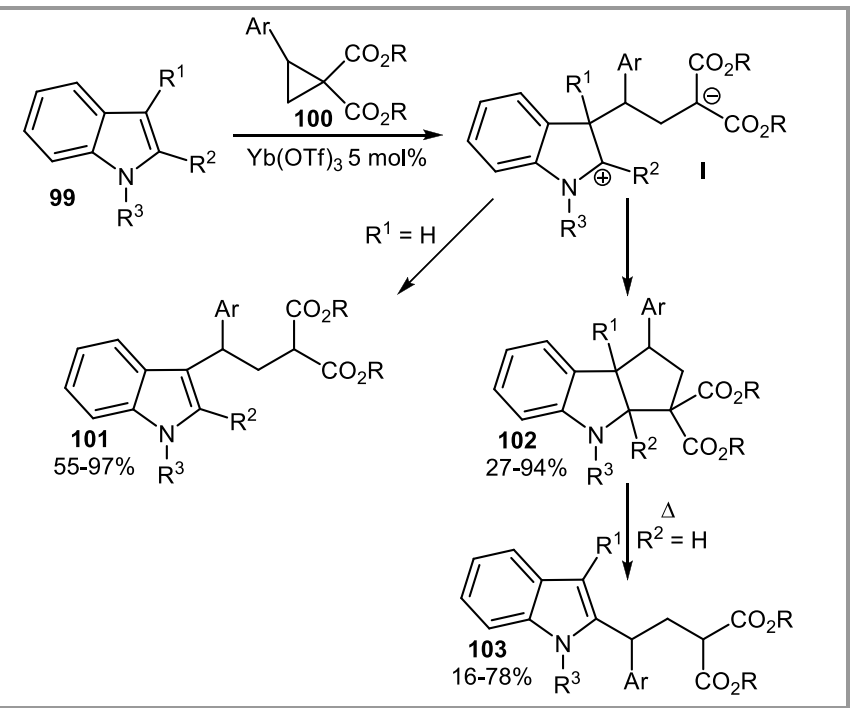

Scheme 24 Reaction of activated cyclopropanes with indole derivatives.

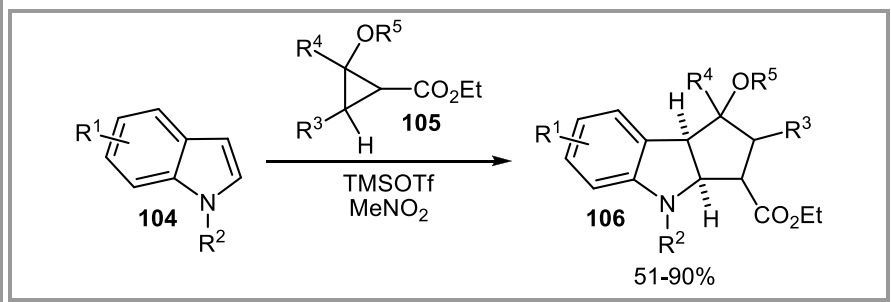

Equation 14

More recently, the scope of electron-rich olefins has been expanded to allyl ${ }^{68 a}$ and allenyl silanes. ${ }^{68 b}$ Efficient catalytic systems for the reaction of donor-acceptor cyclopropanes with enol silyl ethers have been developed using triflimide or scandium triflate as catalysts. ${ }^{69}$

Acetylene have also been used as two carbons partners. ${ }^{70}$ In 2004, Yadav and Sriramurthy reported the first general use of terminal acetylenes $\mathbf{1 0 8}$ using a silyl group to activate the cyclopropane 107 (Equation 15). ${ }^{70 \mathrm{~b}}$ In 2008, Qi and Ready used silyl ynol ethers $\mathbf{1 1 1}$ in the cycloaddition reaction with donor-acceptor cyclopropanes $\mathbf{1 1 0}$ (Equation 16). ${ }^{71}$ Direct treatment of the reaction mixture with HF॰pyridine led to silyl group removal followed by $\beta$-elimination to form cyclopentanones 112. Interestingly, Qi and Ready showed that only air-aged $\mathrm{Me}_{2} \mathrm{AlCl}$ was able to promote the reaction in good yield. They proposed that oxidation of one of the Al-carbon bond led to a Lewis acid more able to promote the reaction. 


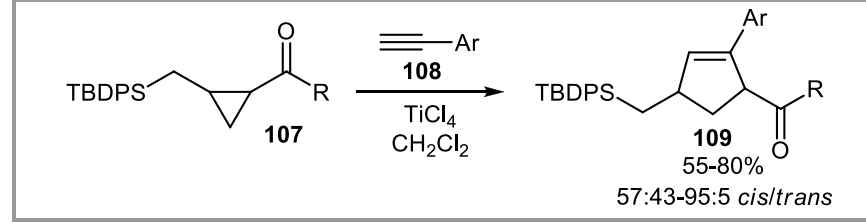

Equation 15

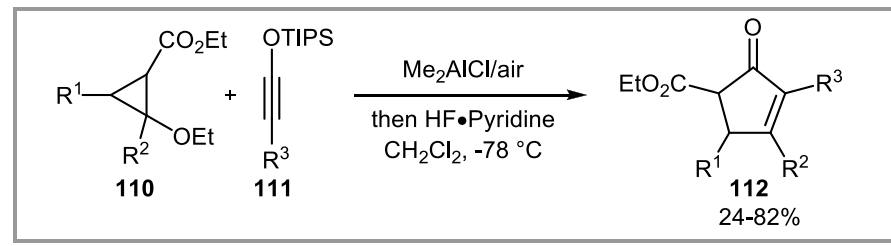

Equation 16

Finally, Liu and Montgomery have introduced a mechanistically new approach for the Ni-catalyzed formal [3+2] cycloaddition of cyclopropyl ketones 113 with Michael acceptors 114 (Equation 17). ${ }^{72}$ This work constituted an important breakthrough in the field, as for the first time simple cyclopropyl ketones could be used in cycloaddition reactions with olefins. Furthermore, good diastereoselectivities were achieved, which has always been a major challenge in this type of cycloaddition reactions. In the first step of the proposed reaction mechanism, oxidative addition of $\mathrm{Ni}(0)$ onto the less hindered cyclopropane C-C bond led to metallacycle I (Scheme 25). As such, this cleavage selectivity is reversed to the one observed with Lewis acid, which is under electronic control. Insertion of olefins $\mathbf{1 1 4}$ was followed by reductive elimination to form product $\mathbf{1 1 6}$ and regenerate the catalyst. The Ti additive was not absolutely necessary for the reaction but led to better yield and shorter reaction time. Cyclopropyl carboxaldehyde could not be used in this reaction, but cycloaddition was successful with the corresponding aldimines. ${ }^{72 b}$

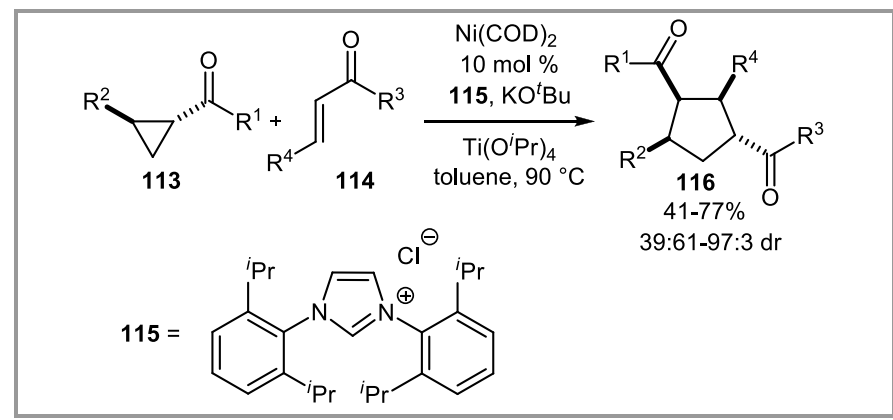

Equation 17

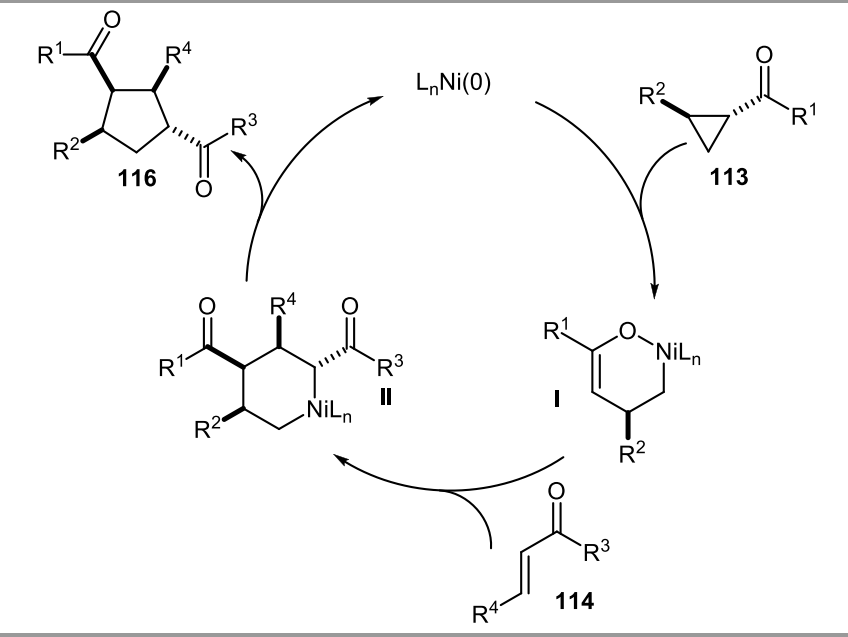

Scheme 25 Proposed mechanism for the Ni-catalyzed formal [3+2] cycloaddition reaction.

\section{2 [3+2] Cycloaddition Reactions with Alde- hydes and Ketones}

The [3+2] formal cycloaddition of activated cyclopropanes and carbonyls give useful tetrahydrofuran derivatives. Most early works focused on the use of donoracceptor cyclopropanes $(\mathbf{1 1 7}, 119$ and 121, Scheme 26, A-C). ${ }^{11 b, 73 a-e}$ Achieving high diastereoselectivities is generally difficult, except in the case of fused ring systems 122 (Scheme 26, C). ${ }^{73 d-e}$ A single example using unsubstituted cyclopropyl ketones $\mathbf{1 2 3}$ was also reported by Oshima and co-workers in 2001 (Scheme 26, D). ${ }^{73 f}$

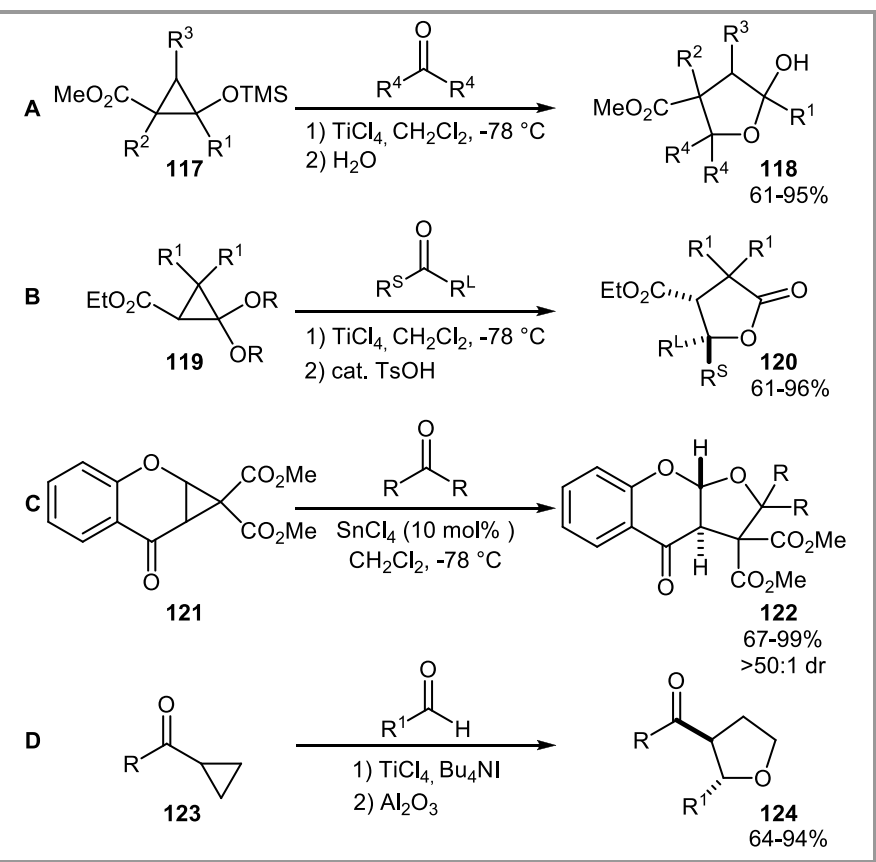

Scheme 26 Selected examples for early reports of cycloaddition reactions of activated cyclopropanes with carbonyl compounds.

In 2006, the scope of donor-acceptor cyclopropanes used in these reactions was expanded to silyl-methyl substituted cyclopropanes by Gupta and Yadav. ${ }^{74}$ 
Since 2005, Johnson and co-workers have studied extensively the Sn or Hf -catalyzed cycloaddition of donoracceptor cyclopropanes $\mathbf{1 2 5}$ with aldehydes (Equation 18). ${ }^{75}$ This work can be considered as a breakthrough in the application of activated cyclopropanes for [3+2] cycloaddition reactions with carbonyl compounds, as not only aromatic substituents could be used on the cyclopropanes and the aldehydes, but also alkenes and even simple alkanes. Furthermore, the reaction was nearly completely diastereoselective and stereospecific, allowing a new access to enantiopure furan derivatives $\mathbf{1 2 6}$ starting from enantiopure cyclopropanes $\mathbf{1 2 5}$. Especially the high stereospecificity is intriguing for this reaction, as racemization would be expected if a defined cationic intermediate was formed. Indeed, the observed regioselectivity for $\mathrm{C}-\mathrm{C}$ bond cleavage is in accordance with an ionic model. To explain these results, Johnson and coworkers proposed a tight-ion pair II as intermediate (Scheme 27). Attack of the aldehyde is followed by a very fast $120{ }^{\circ} \mathrm{C} \mathrm{C}-\mathrm{C}$ bond rotation towards a sterically favored envelope conformation IV, where all the substituents are in a pseudo-equatorial conformation. From this intermediate, a very fast $\mathrm{C}-\mathrm{C}$ bond formation is possible, before any racemization can occur. The complete stereospecificity observed using deuterated ester 127 further supported the proposed mechanism. Several other groups have also proposed similar tight ion-pairs as intermediates. $^{76}$

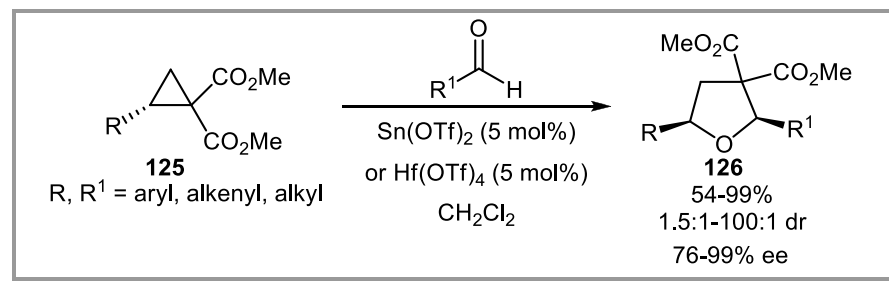

Equation 18

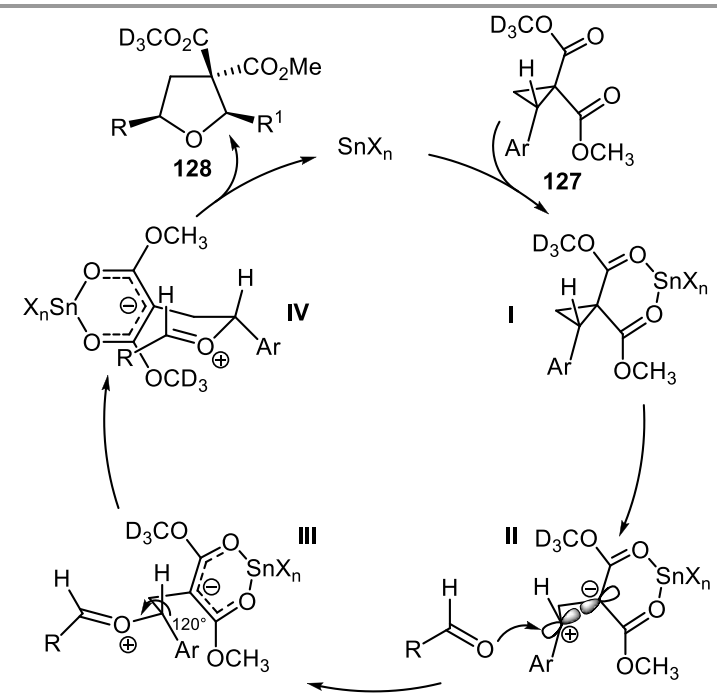

Scheme 27 Proposed mechanism for the stereospecific cycloaddition of activated cyclopropanes with aldehydes.
During their work, Johnson and co-workers observed that in the presence of more electron-rich substituents, racemization was indeed observed if the reaction time was too long. This observation lead to the development of the first catalytic asymmetric [3+2] cycloaddition of aldehydes to racemic cyclopropanes $\mathbf{1 2 9}$ via dynamic resolution (Equation 19). ${ }^{77}$ In this case, high enantioselectivity could be achieved by the use of a Mg catalyst together with a chiral PYBOX ligand $\mathbf{1 3 0}$.

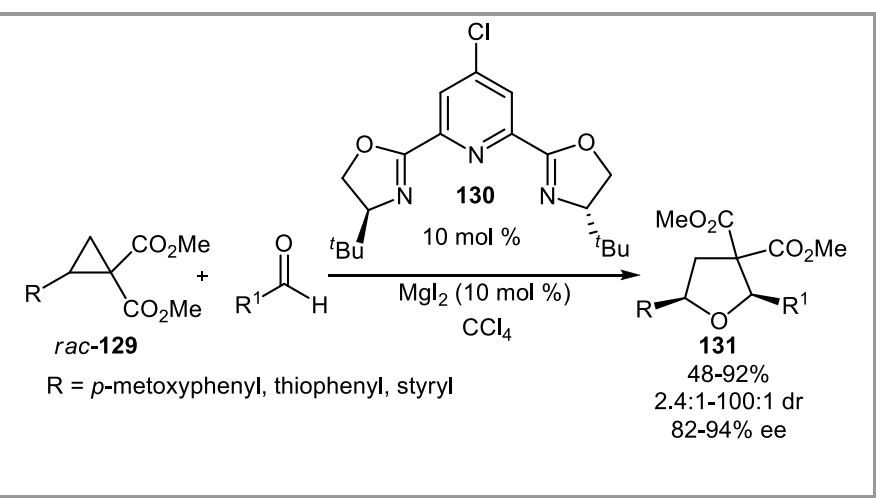

Equation 19

In 2008, Johnson and co-workers also reported a mechanistically different approach using $\operatorname{Pd}(0)$ catalysis (Scheme 28) ${ }^{78}$ As this method is based on the formation of stabilized Pd-allyl intermediate $\mathbf{I}$ and $\mathbf{I I}$, it is limited to activated vinyl-cyclopropanes like $\mathbf{1 3 2}$ as substrates.

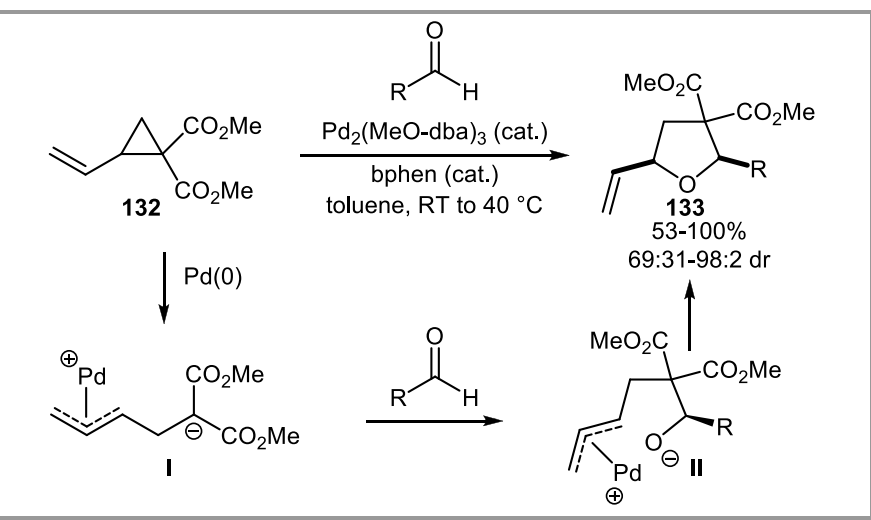

Scheme 28 Pd-catalyzed [3+2] cycloaddition of activated vinyl cyclopropane $\mathbf{1 3 2}$ with aldehydes.

\section{3 [3+2] Cycloaddition Reactions with Imines and Nitriles}

The [3+2] formal cycloaddition of activated cyclopropanes with imines leads to useful pyrrolidine heterocycles, which are omnipresent in natural products and pharmaceutical substances. A first useful process was developed for the synthesis of spiro[pyrrolidin-3,3'oxindoles] 135 by Carreira and co-workers using $\mathrm{MgI}_{2}$ as catalyst (Scheme 29). ${ }^{79}$ In fact, the idea to use double activation using a Lewis acid like magnesium and a nucleophile like iodide has been highly successful in the chemistry of activated cyclopropanes. Ring-opening with iodide led to a nucleophilic magnesium enolate interme- 
diate I, which then reacted with the imine. Intramolecular nucleophilic substitution in II then afforded the pyrrolidines $\mathbf{1 3 5}$ in good yield and diastereoselectivity.

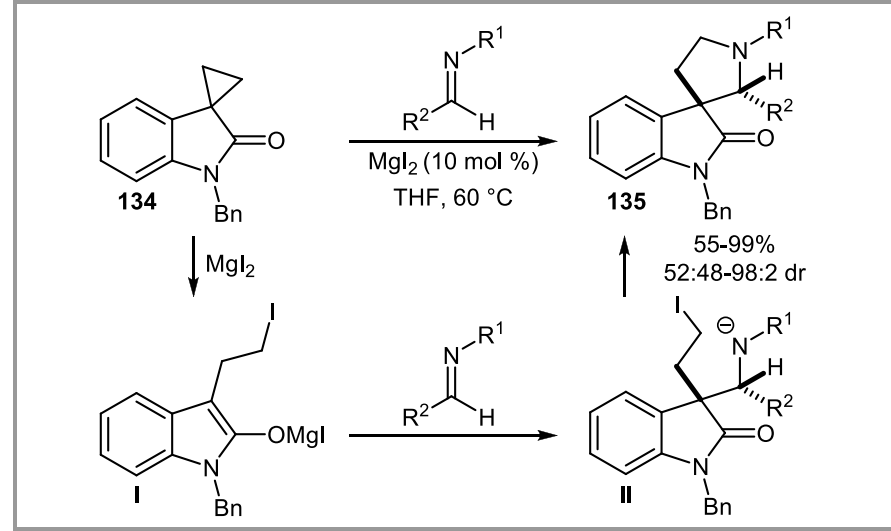

Scheme 29 Formal [3+2] cycloaddition reaction for the synthesis of spiro[pyrrolidin-3,3'-oxindoles] 135.

In 2002, Olsson and co-workers demonstrated that this approach could be applied for a one-pot synthesis of pyrrolidine heterocycles 137 starting directly from cyclopropyl ketones 136, aldehydes and amines with good anti selectivity (Equation 20). ${ }^{80}$ Since these preliminary reports, the methodology has proven useful for the synthesis of diverse pyrrolidine heterocycles. ${ }^{81}$

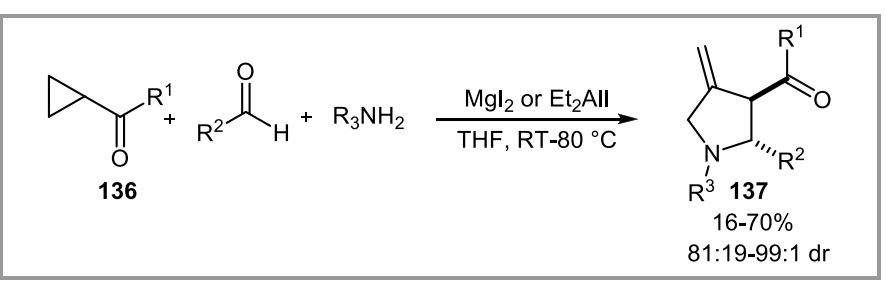

Equation 20

Kerr and co-workers further studied the intramolecular variation of the cycloaddition reaction. ${ }^{82}$ In this case, a striking dependence of the diastereoselectivity from the order of addition of the reagents was observed (Scheme 30). When the aldehyde was added first, selective condensation to the more stable trans oxime 141 occurred (Scheme 31). Cyclopropane ring opening and cyclization then led selectively to the trans product 139. If the Lewis acid was added first, attack onto cyclopropane $\mathbf{1 3 8}$ preceded condensation. To avoid an $\mathrm{A}^{1,3}$ interaction with the diester substituent, formation of cis oxime intermediate II was favored to give selectively the cis product 140 after cyclization.

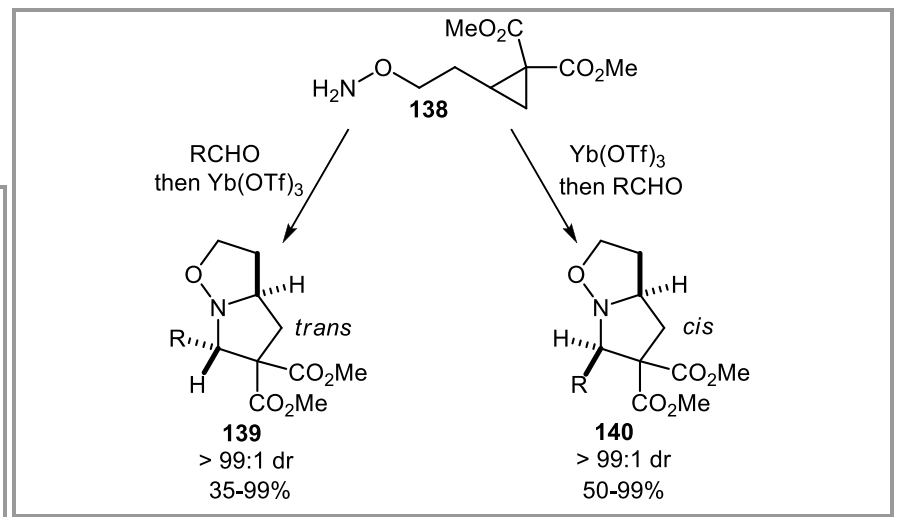

Scheme 30 Diastereoselective intramolecular cycloaddition of imines and activated cyclopropanes depending on reaction conditions.

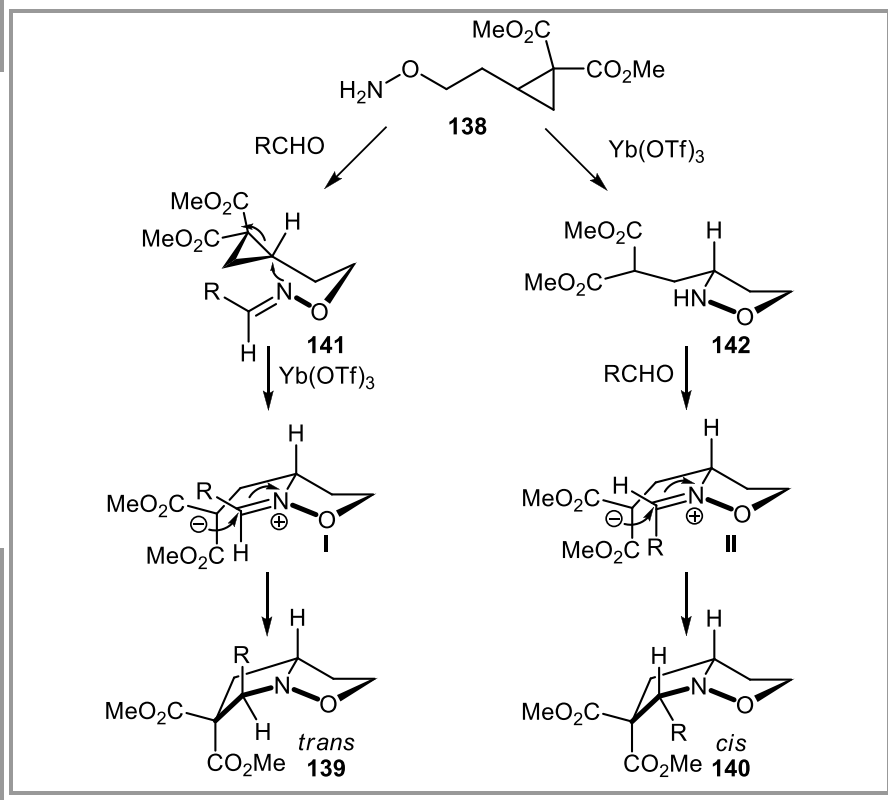

Scheme 31 Proposed mechanism rationalizing the observed diastereoselectivity for the intramolecular cycloaddition of oximes with activated cyclopropanes.

The use of activated methylene cyclopropanes 143 opens several different pathways for reactivity, as a conjugate enolate $\mathbf{I}$ is formed upon ring-opening (Scheme 32). ${ }^{83} \mathrm{In}$ 2002, Lautens and co-workers first reported that $\alpha$ alkylation followed by intramolecular alkylation was observed with diphenylamide substrates and $\mathrm{MgI}_{2}$ as Lewis acid to give pyrrolidine 144 (pathway a), whereas 147 was obtained via $\gamma$ alkylation followed by intramolecular acylation with oxazolidinone imides and $\mathrm{MgI}_{2}$ as Lewis acid (pathway d). ${ }^{83 a}$ In 2007, they further reported that $\gamma$ alkylation followed by intramolecular alkylation was possible for diphenyl amides in the presence of MAD and ${ }^{n} \mathrm{Bu} 4 \mathrm{NI}$ to give pyrrolidine 146 (pathway c). ${ }^{83 \mathrm{c}}$ The last possibility, $\alpha$ alkylation followed by intramolecular acylation leading to $\mathbf{1 4 5}$, has not been reported so far (pathway d). The Lautens groups further developed an asymmetric synthesis of pyrrolidines 144 from methylenecyclopropanes 143 using either an imine 148 bearing a sulfoxide chiral auxiliary (Equation 21) ${ }^{83 \mathrm{~b}}$ or a chiral catalyst (Mg-Box system, Equation 22). ${ }^{83 \mathrm{~d}}$ 


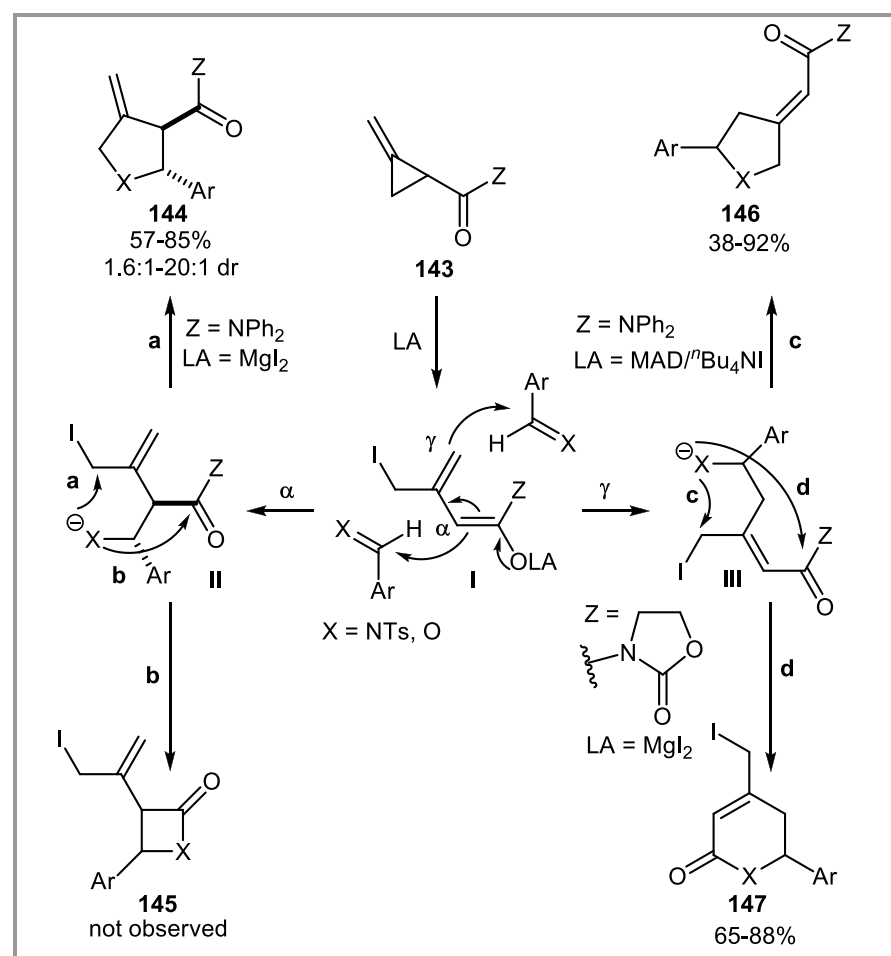

Scheme 32 Activated methylene cyclopropanes 143, versatile intermediate for diverse formal cycloaddition reactions.

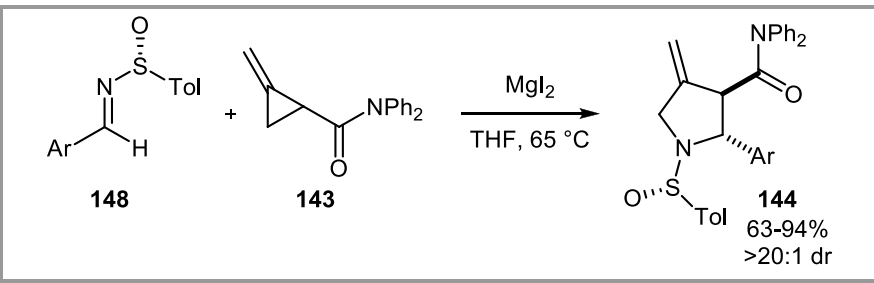

Equation 21

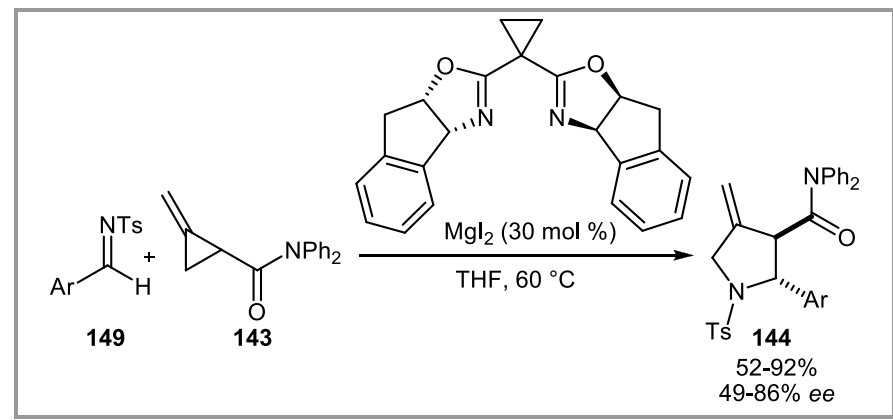

Equation 22

The reaction of activated cyclopropanes with nitrogencontaining electrophiles is not limited to imine derivatives. Pagenkopf and co-workers reported the cycloaddition of nitriles with oxygen-substituted donor-acceptor cyclopropanes. ${ }^{84}$ Depending on the substrate, the obtained dihydropyrroles $\mathbf{1 5 1}$ were stable (Equation 23) (44a $^{8}$ or subsequent elimination of the oxygen substituent was observed to form the corresponding pyrrole heterocycles 153 (Equation 24). Finally, cycloaddition reactions involving the nitrogen atom of pyridines 155 (Equation $25)^{85}$ and indoles 157 (Equation 26) were also successful. ${ }^{86}$

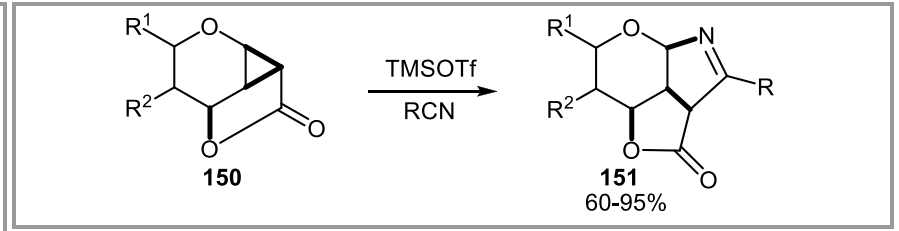

Equation 23

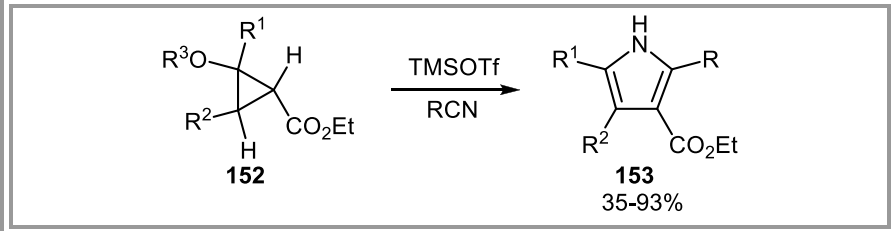

Equation 24

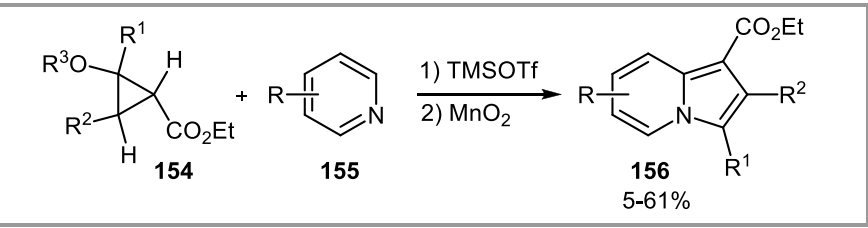

Equation 25

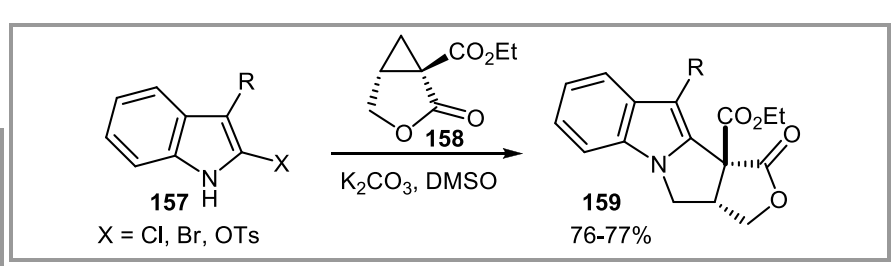

Equation 26

4.4 [3+2] Cycloaddition Reactions with Other Electrophiles

The use of other electrophiles in [3+2] cycloaddition reactions with activated cyclopropanes has not yet been studied extensively. Nevertheless, single examples of cycloaddition reactions involving carbon disulfide, ${ }^{87 a}$ phenylisocyanate, ${ }^{87 \mathrm{~b}}$ phenylisothiocyanate, ${ }^{87 \mathrm{c}} \mathrm{di}-$ azenes, ${ }^{87 \mathrm{~d}, 87 \mathrm{e}}$ nitrosyl chloride ${ }^{87 \mathrm{f}}$ and isonitriles ${ }^{87 \mathrm{~g}}$ have already been reported.

\section{Other Cycloaddition Reactions}

\section{$5.1[3+3]$ Cycloaddition Reactions}

In contrast to [3+2] cycloadditions, [3+3] cycloaddition reactions have been developed only more recently. In 2002, Junjappa and co-workers reported the dimerization of indole substituted cyclopropyl ketones, which constituted a formal $[3+3]$ cycloaddition reaction. ${ }^{88}$ The formed 6-membered rings was further oxidized to the corresponding benzene derivatives. The first useful [3+3] cycloaddition reaction involving nitrones $\mathbf{1 6 0}$ and activated cyclopropanes $\mathbf{1 6 1}$ was then introduced by Kerr and co-workers in 2003. ${ }^{89}$ Activation of cyclopropane dicarboxylate with mild Lewis acids like $\mathrm{Yb}(\mathrm{OTf})_{3}{ }^{89 \mathrm{a}}$ or $\mathrm{MgI}_{2}{ }^{89 \mathrm{c}}$ led to the corresponding tetrahydro-oxazine heterocycles $\mathbf{1 6 2}$ in good yield and cisselectivity (Equation 27). DFT studies showed that both 
a concerted asynchronous pathway and a stepwise pathway with nucleophilic attack of the oxygen atom of the nitrone on the cyclopropane preceding cyclization were possible. ${ }^{89 \mathrm{~d}}$ In all cases, further activation of the cyclopropane by the Lewis acid was essential. Studies using more substituted cyclopropanes 163 and 165 allowed a better understanding of the observed diastereoselectivity (Scheme 33). ${ }^{89 \mathrm{f}}$ Using cis substituted cyclopropane 163, the usual 1,4-cis selectivity was observed. The reaction was proposed to occur stepwise. Attack of the oxygen atom of nitrone $\mathbf{1 6 0}$ led to a zwitterionic intermediate $\mathbf{I}$. Cyclization then proceeded via a favored chair transition state. In the case of trans substituted cyclopropane $\mathbf{1 6 5}$, the reaction was much slower and the 1,4-trans tetrahydro-oxazine 166 was the major product. In this case, the chair conformer II was destabilized by a severe 1,3 diaxial interaction between the $\mathrm{Me}$ and the $\mathrm{Ph}$ groups. Instead, a boat conformer III leading to the 1,4-trans product 166 was favored.

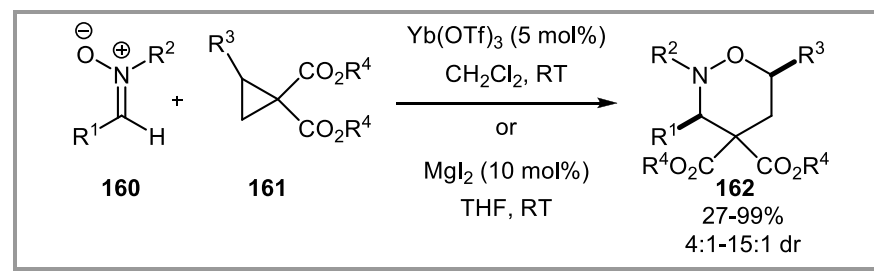

Equation 27

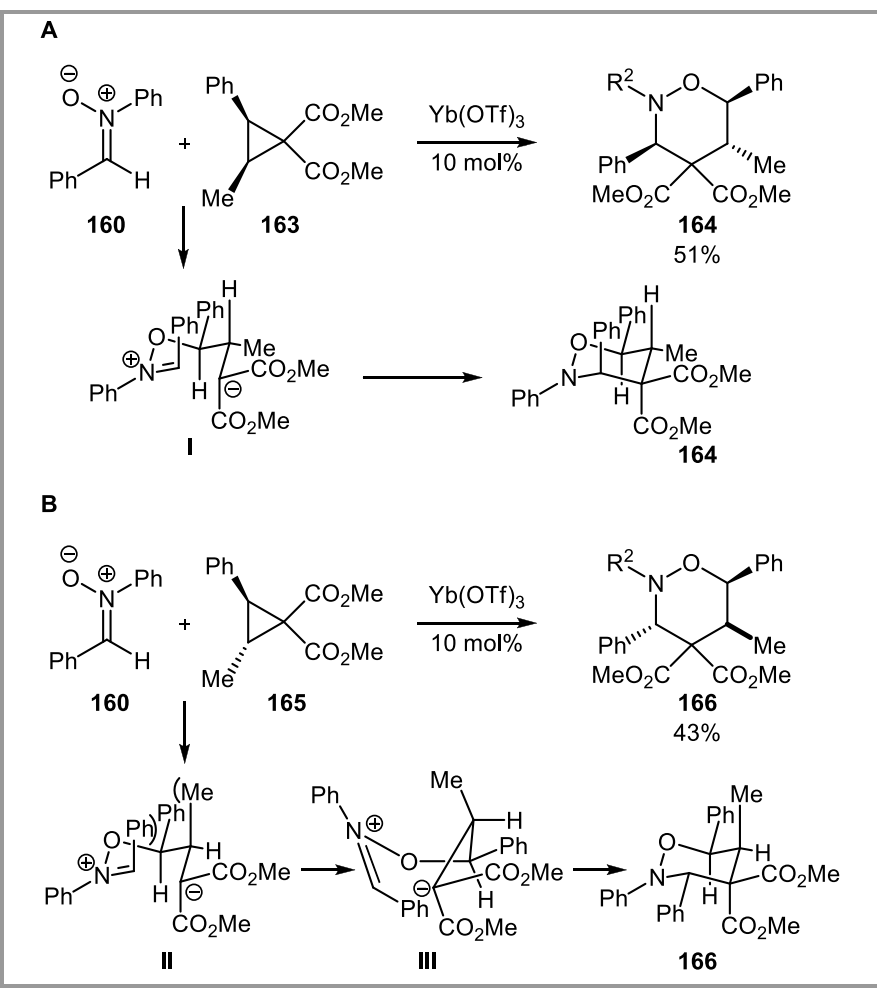

Scheme 33 Diastereoselectivity of the [3+3] cycloaddition reaction of nitrones and activated cyclopropanes and proposed rationalization.

In 2005, Sibi and co-workers developed the first catalytic asymmetric [3+3] cycloaddition of nitrones 160 with activated cyclopropanes 167 using a Ni catalyst with PhDBFOX as ligand (Equation 28). ${ }^{90}$ Tang and co-workers reported the kinetic resolution of chiral activated cyclopropanes 169 via the [3+3] cycloaddition reaction using a Ni catalyst with a trisoxazoline ligand 170 (Equation 29). ${ }^{91}$ Finally, Wang and co-workers used methylene cyclopropanes in the cycloaddition reaction ${ }^{92}$ and $\mathrm{Wu}$ and co-workers developed a domino reaction involving cyclization of an alkyne onto an oxime followed by $[3+3]$ cycloaddition. ${ }^{93}$

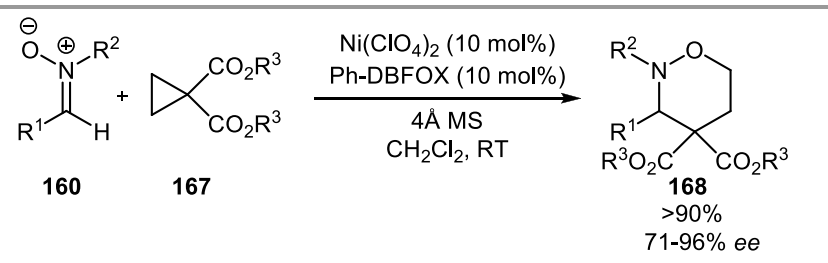

Equation 28

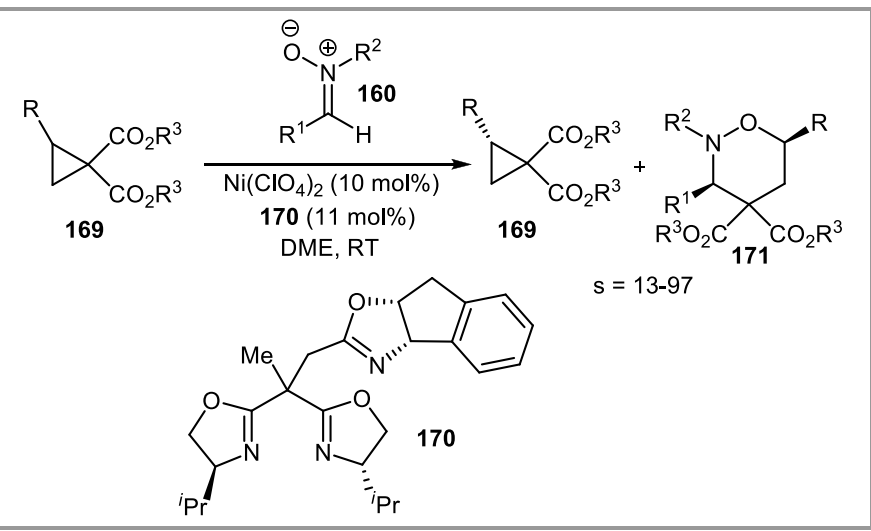

Equation 29

Other [3+3] cycloaddition involving activated cyclopropanes have been much less investigated. Charette and co-workers reported the $[3+3]$ cycloaddition of azomethine imines 172 with activated cyclopropanes 173 (Equation 30). ${ }^{94}$ Finally, Kerr and Sapeta studied the formal $[3+3]$ cycloaddition reaction of activated cyclopropanes with trimethylene methane equivalents (2chloromethyl allyl silanes). However, a two step procedure was necessary in this case. ${ }^{95}$

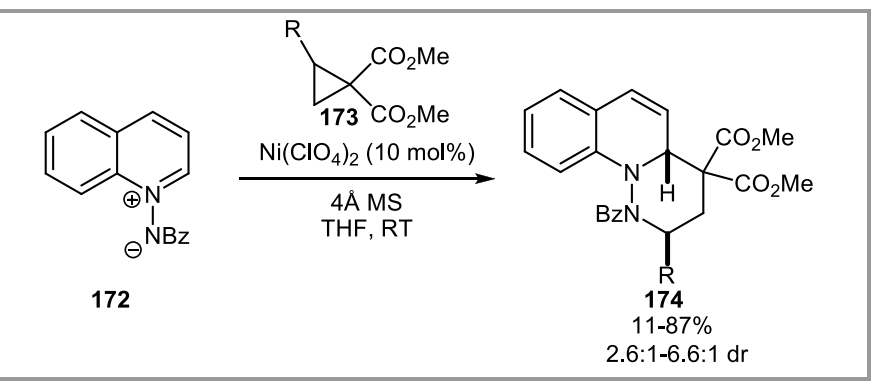

Equation 30

\subsection{Other Cycloaddition Reactions}

$[3+2]$ and [3+3] cycloaddition reactions are by far the most often used cycloaddition reactions using activated cyclopropanes. In principle, other cycloaddition reac- 
tions are also possible. A rare example of [4+3] cycloaddition reaction has been reported by Ivanova and coworkers in $2008 .{ }^{96}$ The $\mathrm{Yb}$ catalyzed cycloaddition of activated cyclopropanes $\mathbf{1 7 5}$ with 1,3diphenylisobenzofuran 176 led to the bicyclic cycloaddition products $\mathbf{1 7 7}$ in good yield with low exo selectivity (Equation 31). ${ }^{96 a}$ Anthracene derivatives could also be used in this cycloaddition reaction. ${ }^{96 \mathrm{~b}}$

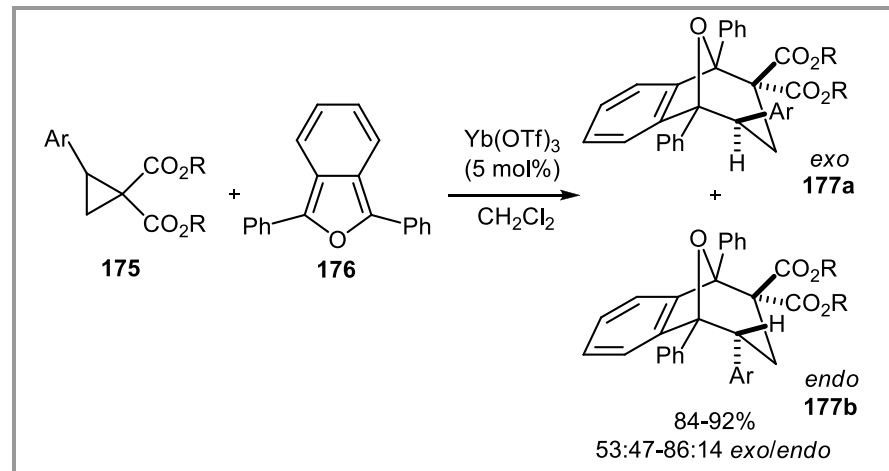

Equation 31

\section{Application in Total Synthesis}

In the 70's, cyclization and cycloisomerization reactions of activated cyclopropanes were extensively studied for the total synthesis of natural products. Seminal pioneering works have been achieved in the group of Danishefsky, ${ }^{8}$ Wenkert ${ }^{10}$ and Stevens. ${ }^{28}$ Since then, these methods have been less extensively used in total synthesis. Based on the work of Danishefsky, ${ }^{56}$ Snyder and co-worker reported in 2001 the use of an activated cyclopropane $\mathbf{1 7 9}$ derived from Meldrum acid for the introduction of a pyrrolidine ring in the total synthesis of Martinellic acid (181) (Scheme 34). ${ }^{97}$

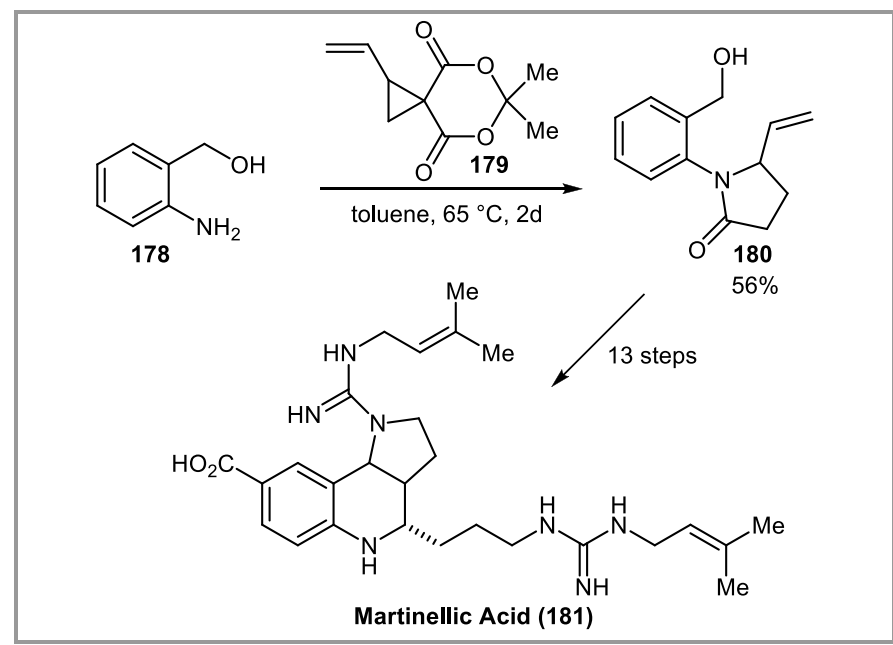

Scheme 34 Synthesis of martinellic acid (181).
Reiser and co-workers used the methodology they had developed for the synthesis of butyrolactones starting from activated cyclopropanes (Scheme 18) for the synthesis of several natural products. ${ }^{53,98}$ Particularly impressive was the addition-ring-opening-cyclization cascade for the synthesis of arglabin (186) reported in 2007 (Scheme 35). ${ }^{98 \mathrm{~b}}$ The sequence began with the diastereoselective $\mathrm{BF}_{3}$-mediated allylation of cyclopropyl aldehyde $\mathbf{1 8 3}$ to give $\mathbf{1 8 4}$. Base initiated cyclopropane opening followed by direct lactonization then led to $\mathbf{1 8 5}$ containing the two 5-membered rings of the natural product.

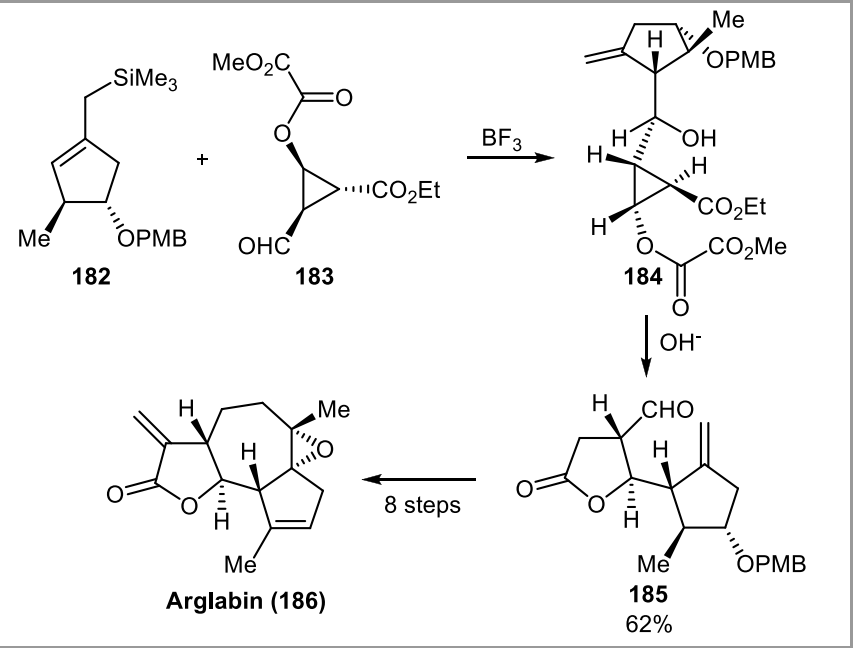

Scheme 35 Total Synthesis of arglabin (186).

In contrast to cyclization reactions, the use of cycloaddition reactions involving activated cyclopropanes in total synthesis has been developed only more recently. The total synthesis of cedrene by Corey and Balanson using a formal intramolecular [3+2] cycloaddition reaction (Scheme 23, E) constituted a notable exception. ${ }^{9}$ The broad potential of this class of reaction became evident when Carreira and co-workers successively disclosed the synthesis of horsfiline (190), strychnofoline (194) and spirotryprostatin B (198) using the [3+2] cycloaddition of imines with oxindole cyclopropanes to form spiro[pyrrolidin-3,3'-oxindoles] (Scheme 36) ${ }^{99}$ In the case of horsfiline (190), ${ }^{99 a}$ methyl imine was generated in situ from the corresponding trimer 188. For strychnofoline (194), ${ }^{99 b, c}$ a cyclic imine 192 was used and only the desired diastereoisomer 193 was obtained. In the case of spirotryprostatin B (198), ${ }^{99 \mathrm{~d}, \mathrm{e}}$ a substituted cyclopropane 195 was needed. The desired diastereoisomer 197 was obtained with 6:1 selectivity for the two centers conserved in the natural product. 


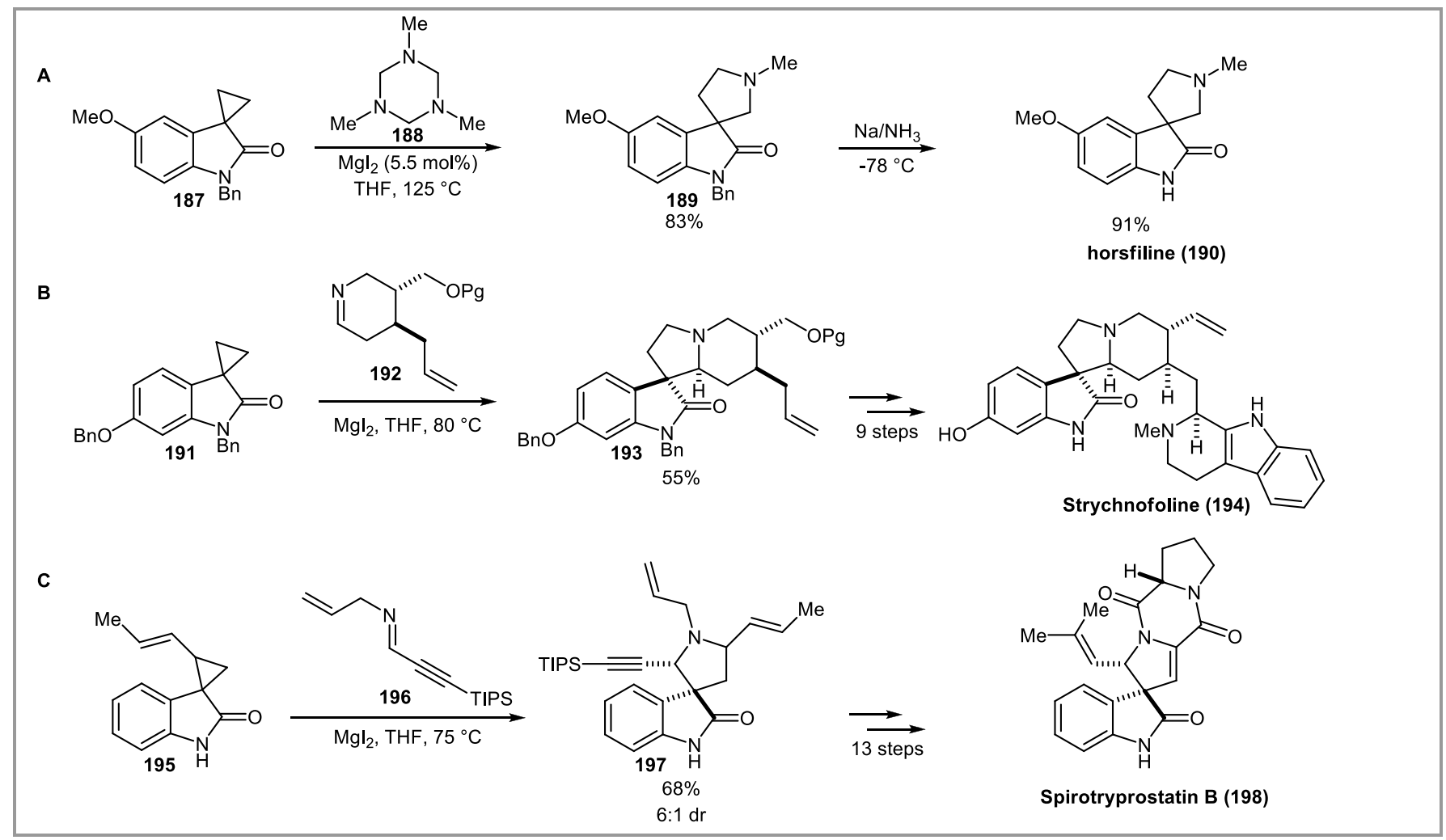

Scheme 36 Synthesis of horsfiline $(\mathbf{1 9 0}, \mathbf{A})$, strychnofoline $(\mathbf{1 9 4}, \mathbf{B})$ and spirotryprostatin B $(\mathbf{1 9 8}, \mathbf{C})$ using the [3+2] cycloaddition of imines and oxindole cyclopropanes.

Leduc and Kerr recently reported the use of their intramolecular [3+2] cycloaddition between oxime and activated cyclopropane for the total synthesis of (-)allosecurinine (202) (Scheme 37). ${ }^{100}$ Cleavage of the N$\mathrm{O}$ bond in bicyclic product 200 led to 201 with the pyrrolidine ring constituting the core of the natural product. Carson and Kerr also made used of an intramolecular cycloaddition between an imine and an activated cyclopropane in $\mathbf{2 0 3}$ to build up the core $\mathbf{2 0 4}$ of the natural product FR901483 (205) (Scheme 38). ${ }^{101}$

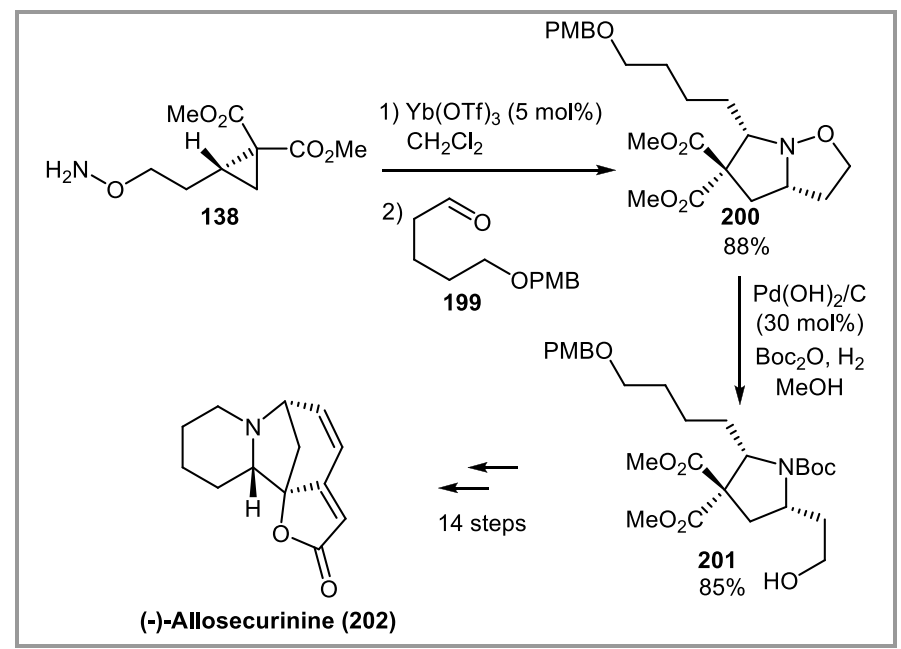

Scheme 37 Total synthesis of (-)-allosecurinine (202).

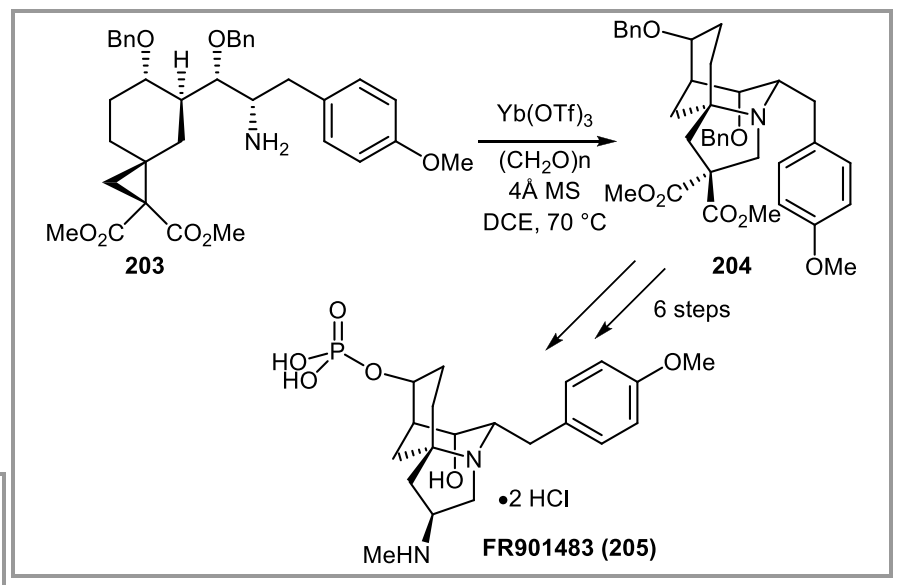

Scheme 38 Total synthesis of FR901483.

Pagenkopf and co-workers used the cyclization of donoracceptor cyclopropane 207 with nitrile 206 for the synthesis of indole alkaloids (Scheme 39) ${ }^{102}$ Tetrahydroindole 208 obtained in the cycloaddition reaction was oxidized in the presence of Pd on carbon to give the corresponding indole 209. Indole 209 could then be converted either to goniomitine $(\mathbf{2 1 0})^{102 a}$ or quebrachamine (211). ${ }^{102 b}$ 


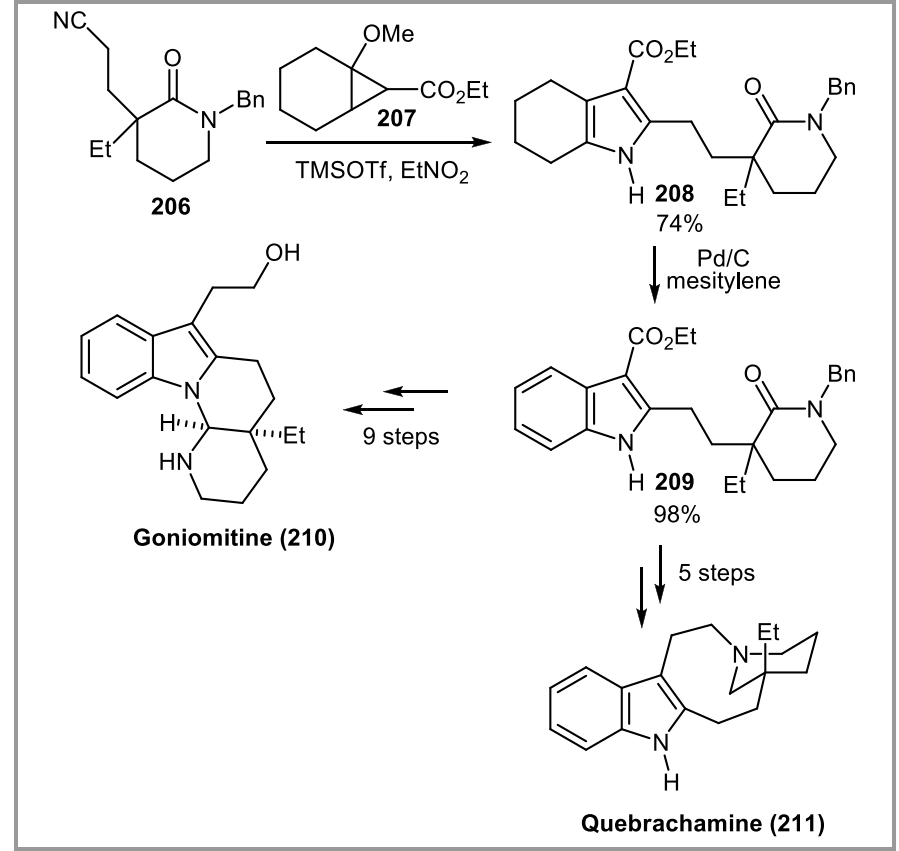

Scheme 39 Total synthesis of goniomitine (210) and quebrachamine (211).

The use of the [3+3] cycloaddition of activated and cyclopropanes for the total synthesis of natural products was studied extensively by the Kerr group. ${ }^{103}$ This reaction allowed an efficient access to tetrahydrooxazine rings containing natural products, as demonstrated in model studies towards the synthesis of FR900482 ${ }^{89 b}$ and in the total synthesis of (+)-phyllantidine (216) by Carson and Kerr in 2006 (Scheme 40). ${ }^{103 a}$

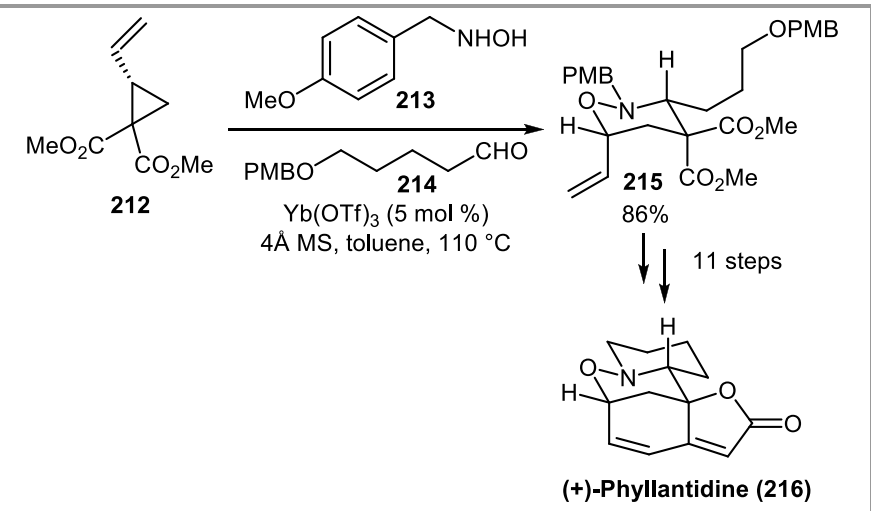

Scheme 40 Total synthesis of (+)-phyllantidine (216).

The use of the $[3+3]$ cycloaddition was not limited to the synthesis of tetrahydrooxxazine ring-containing natural products. Indeed, the $\mathrm{N}-\mathrm{O}$ bond was easily cleaved to give the amino alcohol. Activation of the alcohol and cyclization gave access to pyrrolidine rings, which are much more frequently encountered in natural products. This strategy led to the successful total synthesis of (+)nakadomarin A (222) by Kerr and co-workers (Scheme 41). ${ }^{103 b, c}$ The ring-cleavage cyclization strategy also allowed access to the core of yuremamine (228), although the total synthesis of this natural product has not been reported yet using this strategy (Scheme 42). ${ }^{103 d}$

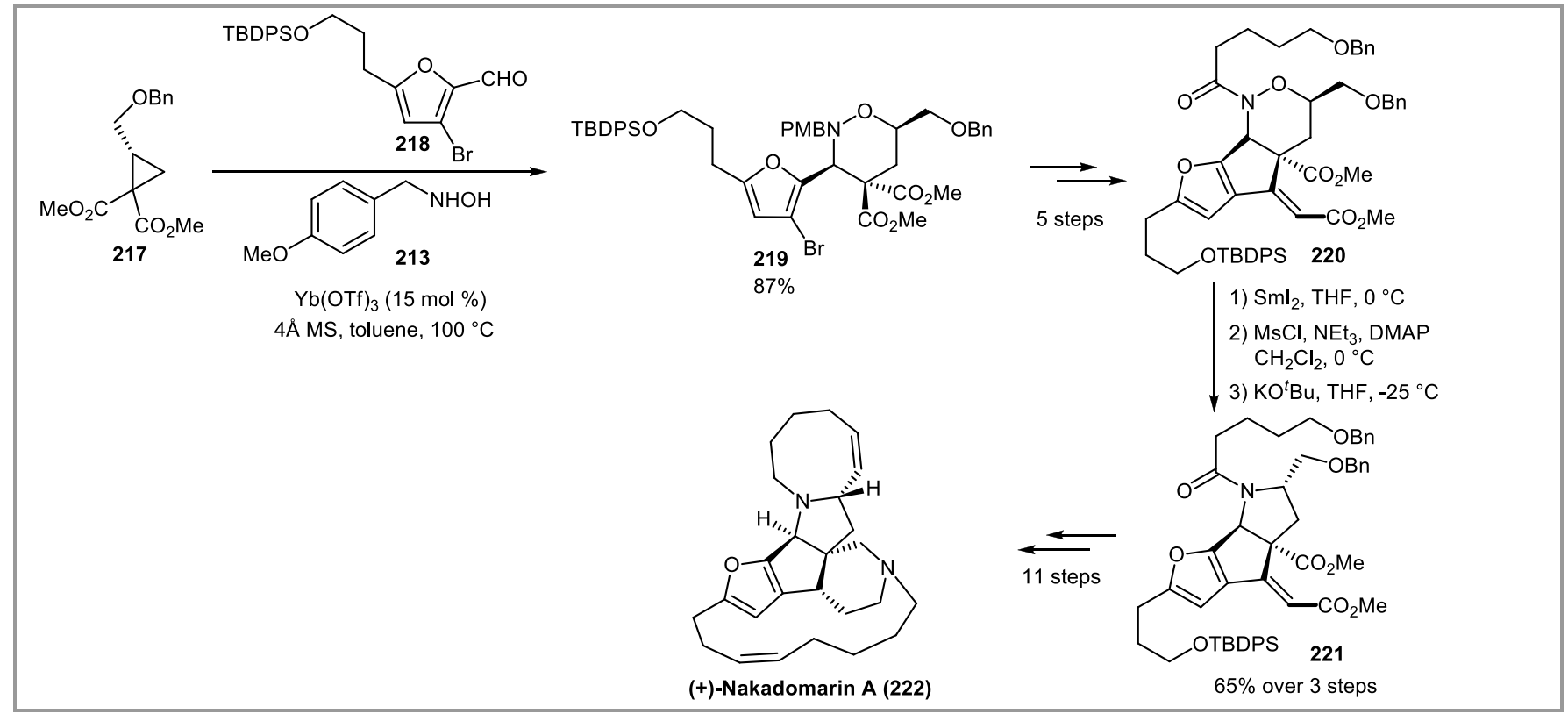

Scheme 41 Total synthesis of (+)-nakadomarin A (222). 


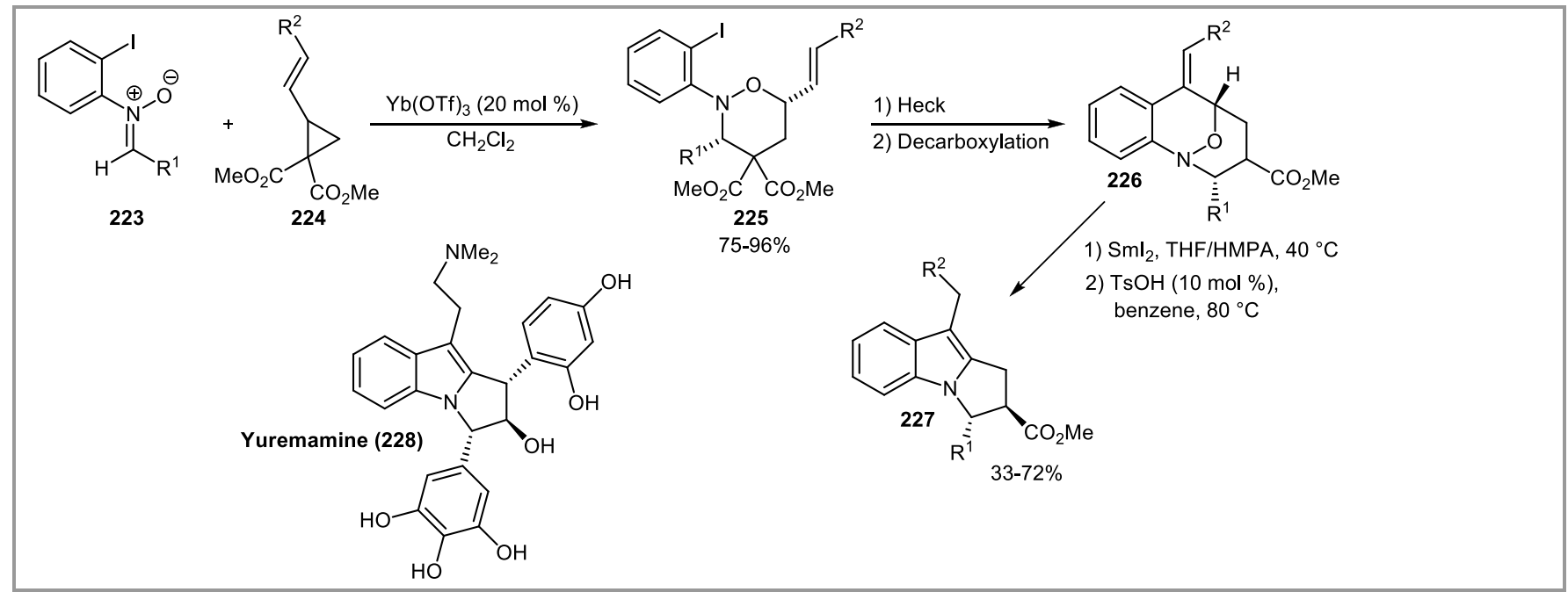

Scheme 42 Model studies towards the total synthesis yuremamine (228).

\section{Conclusion}

Since the "golden age" of the 70's, cyclization and cycloaddition reactions of activated cyclopropanes have been used regularly in organic synthesis. However, it is only more recently that their broad potential in conjunction with modern catalytic methods has been fully recognized. As more and more efficient cyclopropanation methods are introduced, the synthesis of activated cyclopropanes becomes easier and their transformations more

\section{Acknowledgment}

The EPFL is acknowledged for financial support. We thank Prof. K. Gademann of the Chemical Synthesis Laboratory at EPFL for proofreading this manuscript.

\section{References}

(1) (a) Reissig, H. U. In The Chemistry of the Cyclopropyl Group; Rappoport, Z., Ed.; John Wiley \& Sons: Chichester, 1987, p 375-443. (b) Carbocyclic Three- and FourMembered Ring Compounds In Houben-Weyl, Methods of Organic chemistry, Vol. E17a, E17b, E17c, E17d; Thieme Verlag: Stuttgart, 1997. (c) Salaun, J. Cyclopropane derivatives and their diverse biological activities In Small Ring Compounds in Organic Synthesis Vi 2000; Vol. 207, p 1-67. (d) Wong, H. N. C.; Hon, M. Y.; Tse, C. W.; Yip, Y. C.; Tanko, J.; Hudlicky, T. Chem. Rev. 1989, 89, 165.

(2) (a) Walsh, A. D. Nature 1947, 159, 712. (b) Walsh, A. D. Trans. Far. Soc. 1949, 45, 179.

(3) (a) Binger, P.; Buch, H. M. Top. Curr. Chem. 1987, 135, 77. (b) Nakamura, I.; Yamamoto, Y. Adv. Synth. Catal. 2002, 344, 111. (c) Brandi, A.; Cicchi, S.; Cordero, F. M.; Goti, A. Chem. Rev. 2003, 103, 1213. (d) Rubin, M.; Rubina, M.; Gevorgyan, V. Synthesis 2006, 1221.

(4) (a) Goldschmidt, Z.; Crammer, B. Chem. Soc. Rev. 1988, 17, 229. (b) Piers, E. In Comprehensive Organic Synthesis; Trost, B. M., Ed.; Pergamon Press: New York, 1991; Vol. 5, p 971-998. (c) Baldwin, J. E. Chem. Rev. 2003, 103, 1197. important. The introduction of highly diastereoselective methods as well as the first catalytic asymmetric methods for [3+2] and [3+3] cycloaddition reaction have opened the way for the use of these processes in more complex settings, as demonstrated by the recent surge of publication on the total synthesis of natural products using these methods. Nevertheless, the field is still in his infancy, and further efforts are needed to control and use the exceptional reactivity of carbonyl and imine cyclopropanes and to fully exploit their potential in organic synthesis.

(5) (a) Wender, P. A.; Takahashi, H.; Witulski, B. J. Am. Chem. Soc. 1995, 117, 4720. (b) Yu, Z. X.; Wender, P. A.; Houk, K. N. J. Am. Chem. Soc. 2004, 126, 9154. (c) Trost, B. M.; Toste, F. D.; Shen, H. J. Am. Chem. Soc. 2000, 122, 2379. (d) Trost, B. M.; Shen, H. C.; Horne, D. B.; Toste, E. D.; Steinmetz, B. G.; Koradin, C. Chem. Eur. J. 2005, 11, 2577.

(6) Bone, W. A.; Perkin, W. H. J. Chem. Soc. Trans. 1895, 67, 108.

(7) (a) Stork, G.; Gregson, M. J. Am. Chem. Soc. 1969, 91, 2373. (b) Stork, G.; Grieco, P. A. J. Am. Chem. Soc. 1969, 91, 2407. (c) Stork, G.; Marx, M. J. Am. Chem. Soc. 1969, 91, 2371. (d) Stork, G.; Grieco, P. A. Tetrahedron Lett. $1971,1807$.

(8) (a) Danishefsky, S., Dynak, J.; Hatch, E.; Yamamoto, M. J. Am. Chem. Soc. 1974, 96, 1256. (b) Danishefsky, S.; Tsai, M. Y.; Dynak, J. J. Chem. Soc. Chem. Commun. 1975, 7. (c) Danishefsky, S.; McKee, R.; Singh, R. K. J. Am. Chem. Soc. 1977, 99, 4783. (d) Danishefsky, S.; McKee, R.; Singh, R. K. J. Am. Chem. Soc. 1977, 99, 7711. (e) Danishefsky, S. Acc. Chem. Res. 1979, 12, 66. (f) Danishefsky, S.; Regan, J.; Doehner, R. J. Org. Chem. 1981, 46, 5255.

(9) Corey, E. J.; Balanson, R. D. Tetrahedron Lett. 1973, 3153.

(10) (a) Wenkert, E.; Alonso, M. E.; Buckwalter, B. L.; Chou, K. J. J. Am. Chem. Soc. 1977, 99, 4778. (b) Wenkert, E. Acc. Chem. Res. 1980, 13, 27.

(11) (a) Reissig, H. U.; Hirsch, E. Angew. Chem., Int. Ed. Engl. 1980, 19, 813. (b) Reissig, H. U. Tetrahedron Lett. 1981, 22, 2981. (c) Bruckner, C.; Reissig, H. U. Angew. Chem., Int. Ed. Engl. 1985, 24, 588. (d) Grimm, E. L.; Reissig, H. U. J. Org. Chem. 1985, 50, 242. (e) Reissig, H. U.;

Reichelt, I.; Lorey, H. Liebiegs Ann. Chem. 1986, 1924. (f) Bruckner, C.; Reissig, H. U. J. Org. Chem. 1988, 53, 2440. 
(g) Reissig, H. U.; Holzinger, H.; Glomsda, G. Tetrahedron 1989, 45, 3139.

(12) For a recent review, see: Pellissier, H. Tetrahedron 2008, 64, 7041.

(13) (a) Reissig, H. U. Top. Curr. Chem. 1988, 144, 73. (b) Reissig, H. U.; Zimmer, R. Chem. Rev. 2003, 103, 1151. (c) Gnad, F.; Reiser, O. Chem. Rev. 2003, 103, 1603. (d) Yu, M.; Pagenkopf, B. L. Tetrahedron 2005, 61, 321.

(14) Rubin, M.; Rubina, M.; Gevorgyan, V. Chem. Rev. 2007, 107, 3117.

(15) Agrawal, D.; Yadav, V. K. Chem. Commun. 2008, 6471.

(16) De Simone, F.; Waser, J. Chimia 2009, 63, 162.

(17) (a) Boykin, D. W.; Lutz, R. E. J. Am. Chem. Soc. 1964, 86, 5046. (b) Pittman, C. U.; McManus, S. P. J. Am. Chem. Soc. 1969, 91, 5915. For a review on the synthesis of fivemembered rings using activated cyclopropanes, see: (c) Kulinkovich, O. G. Uspekhi Khimii 1993, 62, 887.

(18) (a) Abdallah, H.; Gree, R.; Carrie, R. Tetrahedron 1985, 41, 4339. (b) Lee, P. H.; Kim, J. S.; Kim, Y. C.; Kim, S. G. Tetrahedron Lett. 1993, 34, 7583. (c) Lund, E. A.; Kennedy, I. A.; Fallis, A. G. Tetrahedron Lett. 1993, 34, 6841.

(19) (a) Alonso, M. E.; Morales, A.; Chitty, A. W. J. Org. Chem. 1982, 47, 3747. (b) Lund, E. A.; Kennedy, I. A.; Fallis, A. G. Can. J. Chem. 1996, 74, 2401. (c) Pirrung, M. C.; Blume, F. J. Org. Chem. 1999, 64, 3642. (d) Muller, P.; Allenbach, Y. F.; Ferri, M.; Bernardinelli, G. Arkivoc 2003, 80. (e) Muller, P.; Bernardinelli, G.; Allenbach, Y. F.; Ferri, M.; Grass, S. Synlett 2005, 1397.

(20) Davies, H. M. L.; Ahmed, G.; Calvo, R. L.; Churchill, M. R.; Churchill, D. G. J. Org. Chem. 1998, 63, 2641.

(21) Bernard, A. M.; Frongia, A.; Piras, P. P.; Secci, F.; Spiga, M. Org. Lett. 2005, 7, 4565.

(22) (a) Su, J. T.; Xiong, J.; Liang, S. C.; Qiu, G. F.; Feng, X. C.; Teng, H. B.; Wu, L. M.; Hu, X. M. Synth. Commun. 2006, 36, 693. (b) Zhang, Z. G.; Zhang, Q.; Sun, S. G.; Xiong, T.; Liu, Q. Angew. Chem., Int. Ed. 2007, 46, 1726. (c) Zhang, R.; Liang, Y. J.; Zhou, G. Y.; Wang, K. W.; Dong, D. W. J. Org. Chem. 2008, 73, 8089.

(23) (a) Nakajima, T.; Segi, M.; Mituoka, T.; Fukute, Y.; Honda, M.; Naitou, K. Tetrahedron Lett. 1995, 36, 1667. (b) Honda, M.; Naitou, T.; Hoshino, H.; Takagi, S.; Segi, M.; Nakajima, T. Tetrahedron Lett. 2005, 46, 7345.

(24) Yadav, V. K.; Balamurugan, R. Org. Lett. 2001, 3, 2717.

(25) (a) Ma, S. M.; Zhang, J. L. Angew. Chem., Int. Ed. 2003, 42, 184. (b) Ma, S. M.; Lu, L. H.; Zhang, J. L. J. Am. Chem. Soc. 2004, 126, 9645. (c) Bowman, R. K.; Johnson, J. S. Org. Lett. 2006, 8, 573.

(26) For a more detailed discussion of the reaction mechanism, see ref. $25 b$

(27) Cloke, J. B. J. Am. Chem. Soc. 1929, 51, 1174.

(28) (a) Stevens, R. V.; Wentland, M. P. Tetrahedron Lett. 1968, 2613. (b) Stevens, R. V.; Ellis, M. C.; Wentland, M. P. J. Am. Chem. Soc. 1968, 90, 5576. (c) Stevens, R. V.; Wentland, M. P. J. Am. Chem. Soc. 1968, 90, 5580. (d) Stevens, R. V.; Luh, Y.; Sheu, J. T. Tetrahedron Lett. 1976, 3799. (e) Stevens, R. V. Acc. Chem. Res. 1977, 10, 193. For a review on the synthesis and use of cyclopropyl imines, see: (f) Soldevilla, A.; Sampedro, D. Org. Prep. Proced. Int. 2007, 39, 561.

(29) (a) Boeckman, R. K.; Jackson, P. F.; Sabatucci, J. P. J. Am. Chem. Soc. 1985, 107, 2191. (b) Giller, K.; Baird, M. S.; De Meijere, A. Synlett 1992, 524.

(30) Tanguy, C.; Bertus, P.; Szymoniak, J.; Larionov, O. V.; De Meijere, A. Synlett 2006, 2339.

(31) (a) Kuduk, S. D.; Ng, C.; Chang, R. K.; Bock, M. G. Tetrahedron Lett. 2003, 44, 1437. (b) Chang, R. K.; DiPardo, R. M.; Kuduk, S. D. Tetrahedron Lett. 2005, 46, 8513.

(32) Yang, Y. H.; Shi, M. J. Org. Chem. 2005, 70, 8645.
(33) For recent examples, see : (a) Kim, C.; Brady, T.; Kim, S. H.; Theodorakis, E. A. Synth. Commun. 2004, 34, 1951. (b) Brady, T. P.; Kim, S. H.; Wen, K.; Kim, C.; Theodorakis, E. A. Chem. Eur. J. 2005, 11, 7175. (c) Weisser, R.; Yue, W. M.; Reiser, O. Org. Lett. 2005, 7, 5353. (d) Haveli, S. D.; Sridhar, P. R.; Suguna, P.; Chandrasekaran, S. Org. Lett. 2007, 9, 1331.

(34) Du, D.; Wang, Z. W. Tetrahedron Lett. 2008, 49, 956.

(35) Schneider, T. F.; Kaschel, J.; Dittrich, B.; Werz, D. B. Org. Lett. 2009, 11, 2317.

(36) (a) Lautens, M.; Han, W.; Liu, J. H. C. J. Am. Chem. Soc. 2003, 125, 4028. (b) Scott, M. E.; Schwarz, C. A.; Lautens, M. Org. Lett. 2006, 8, 5521.

(37) Scott, M. E.; Bethuel, Y.; Lautens, M. J. Am. Chem. Soc. 2007, 129, 1482.

(38) (a) Yamagata, K.; Okabe, F.; Maruoka, H.; Tagawa, Y. J. Heterocycl. Chem. 2005, 42, 543. (b) Wiedemann, S. H.; Noda, H.; Harada, S.; Matsunaga, S.; Shibasaki, M. Org. Lett. 2008, 10, 1661.

(39) (a) Campos, P. J.; Soldevilla, A.; Sampedro, D.; Rodriguez, M. A. Tetrahedron Lett. 2002, 43, 8811. (b) Mangelinckx, S.; De Kimpe, N. Synlett 2005, 1521.

(40) Mangelinckx, S.; De Kimpe, N. Synlett 2006, 369.

(41) (a) Du, D.; Wang, Z. W. Eur. J. Org. Chem. 2008, 4949. (b) Li, G. Q.; Dai, L. X.; You, S. L. Org. Lett. 2009, 11, 1623.

(42) (a) Sohn, S. S.; Bode, J. W. Angew. Chem., Int. Ed. 2006, 45, 6021. (b) Phillips, E. M.; Reynolds, T. E.; Scheidt, K. A. J. Am. Chem. Soc. 2008, 130, 2416.

(43) (a) Murphy, W. S.; Wattanasin, S. Tetrahedron Lett. 1980, 21, 1887. (b) Murphy, W. S.; Wattanasin, S. J. Chem. Soc. Perkin Trans. 1 1981, 2920. (c) Murphy, W. S.; Wattanasin, S. J. Chem. Soc. Perkin Trans. 1 1982, 1029. (d) Murphy, W. S.; Wattanasin, S. J. Chem. Soc. Perkin Trans. 1 1982, 271.

(44) (a) I. N. Nazarov, I. I. Zaretskaya, Izv. Akad. Nauk. SSSR. Ser. Khim. 1941, 211. (b) K. L. Habermas, S. E. Denmark, T. K. Jones, Org. React. (N. Y.) 1994, 45, 1-158. For recent reviews, see: (c) M. A. Tius, Eur. J. Org. Chem. 2005, 2193. (d) A. J. Frontier, C. Collison, Tetrahedron 2005, 61, 7577. (e) H. Pellissier, Tetrahedron 2005, 61, 6479.

(45) L. Greiner-Bechert, T. Sprang, H. H. Otto, Mon. Chem. 2005, 136, 635.

(46) Yadav, V. K.; Kumar, N. V. Chem. Commun. 2008, 3774.

(47) Tsuge, O.; Kanemasa, S.; Otsuka, T.; Suzuki, T. Bull. Chem. Soc. Jpn. 1988, 61, 2897.

(48) De Simone, F.; Andres, J.; Torosantucci, R.; Waser, J. Org. Lett. 2009, 11, 1023.

(49) He, W.; Herrick, I. R.; Atesin, T. A.; Caruana, P. A.; Kellenberger, C. A.; Frontier, A. J. J. Am. Chem. Soc. 2008, $130,1003$.

(50) (a) Deb, B.; Asokan, C. V.; Ila, H.; Junjappa, H. Tetrahedron Lett. 1988, 29, 2111. (b) Deb, B.; Ila, H.; Junjappa, H. J. Chem. Res.-S 1990, 356. (c) Patro, B.; Deb, B.; Ila, H.; Junjappa, H. J. Org. Chem. 1992, 57, 2257. (d) Patra, P. K.; Patro, B.; Ila, H.; Junjappa, H. Tetrahedron Lett. 1993, 34, 3951. (e) Patra, P. K.; Sriram, V.; Ila, H.; Junjappa, H. Tetrahedron 1998, 54, 531. (f) Nandi, S.; Kumar, U. K. S.; Ila, H.; Junjappa, H. J. Org. Chem. 2002, 67, 4916. (g) Venkatesh, C.; Ila, H.; Junjappa, H.; Mathur, S.; Hucht, V. J. Org. Chem. 2002, 67, 9477. (h) Peruncheralathan, S.; Sriram, V.; Ila, H.; Junjappa, H. Tetrahedron 2004, 60, 5603. (i) Yadav, A. K.; Peruncheralathan, S.; Ila, H.; Junjappa, H. J. Org. Chem. 2007, 72, 1388. (j) Yadav, S. K. S.; Yadav, A. K.; Sundaram, G. S. M.; Ila, H.; Junjappa, H. Arkivoc 2007, 231.

(51) See also: P. A. Grieco, S. Finkelhor, Tetrahedron Lett. 1974, 527. 
(52) (a) Smith, A. B.; Dieter, R. K. Tetrahedron 1981, 37, 2407. (b) Smith, A. B.; Dieter, R. K. J. Am. Chem. Soc. 1981, 103, 2017.

(53) Fuerst, D. E.; Stoltz, B. M.; Wood, J. L. Org. Lett. 2000, 2, 3521.

(54) Bohm, C.; Reiser, O. Org. Lett. 2001, 3, 1315.

(55) Hu, B.; Xing, S. Y.; Wang, Z. W. Org. Lett. 2008, 10, 5481.

(56) Singh, R. K.; Danishefsky, S. J. Org. Chem. 1976, 41, 1668.

(57) (a) Yang, Y. H.; Shi, M. J. Org. Chem. 2005, 70, 10082.

(b) Yang, Y. H.; Shi, M. Eur. J. Org. Chem. 2006, 5394.

(c) Yang, Y. H.; Shi, M. Org. Lett. 2006, 8, 1709. (d) Shi,

M.; Tang, X. Y.; Yang, Y. H. Org. Lett. 2007, 9, 4017. (e) Shi, M.; Tang, X. Y.; Yang, Y. H. J. Org. Chem. 2008, 73, 5311.

(58) (a) Celerier, J. P.; Haddad, M.; Jacoby, D.; Lhommet, G. Tetrahedron Lett. 1987, 28, 6597. (b) Budynina, E. M.; Yashin, N. V.; Ivanova, O. A.; Averina, E. B.; Kuznetsova, T. S.; Shpanchenko, R. V.; Zefirov, N. S. Dokl. Chem. 2001, 381, 307. (c) Shi, M.; Yang, Y. H.; Xu, B. Synlett 2004, 1622. (d) Haidar, P.; Guin, J.; Ray, J. K. Tetrahedron Lett. 2005, 46, 1071. (e) Haldar, P.; Barman, G.; Ray, J. K. Tetrahedron 2007, 63, 3049. (f) Maruoka, H.; Okabe, F.; Yamagata, K. J. Heterocycl. Chem. 2007, 44, 201. (g) Cao, W. G.; Zhang, H.; Chen, J.; Deng, H. M.; Shao, M.; Lei, L.; Qian, J. X.; Zhu, Y. Tetrahedron 2008, 64, 6670.

(59) Wurz, R. P.; Charette, A. B. Org. Lett. 2005, 7, 2313.

(60) Lu, L. H.; Chen, G. F.; Ma, S. M. Org. Lett. 2006, 8, 835.

(61) (a) Zefirov, N. S.; Kozhushkov, S. I.; Kuznetsova, T. S. Tetrahedron 1982, 38, 1693. (b) Zefirov, N. S.; Kozhushkov, S. I.; Kuznetsova, T. S.; Ershov, B. A.; Selivanov, S. I. Tetrahedron 1986, 42, 709. (c) Wang, K.; Xiang, D.; Liu, J. Y.; Pan, W.; Dong, D. Org. Lett. 2008, 10, 1691. (d) Langer, P.; Bose, G. Angew. Chem. Int. Ed. 2003, 42, 4033. (e) Bose, G.; Nguyen, V. T. H.; Ullah, E.; Lahiri, S.; Gorls, H.; Langer, P. J. Org. Chem. 2004, 69, 9128. (f) Hefner, J.; Langer, P. Tetrahedron Lett. 2008, 49, 4470. (g) Rashid, M. A.; Iqbal, I.; Rasool, N.; Imran, M.; Langer, P. Tetrahedron Lett. 2008, 49, 2466. (h) Riahi, A.; Lau, M.; Reinke, H.; Fischer, C.; Langer, P. Tetrahedron 2009, 65, 5491.

(62) (a) Zhang, J. L.; Schmalz, H. G. Angew. Chem., Int. Ed. 2006, 45, 6704. (b) Fang, R.; Su, C. Y.; Zhao, C. Y.; Phillips, D. L. Organometallics 2009, 28, 741.

(63) Huang, X.; Fu, W. J.; Miao, M. Z. Tetrahedron Lett. 2008, 49, 2359.

(64) Huang, X.; Miao, M. Z. J. Org. Chem. 2008, 73, 6884.

(65) (a) Dolfini, J. E.; Menich, K.; Corliss, P. Tetrahedron Lett. 1966, 4421. (b) Berkowitz, W. F.; Grenetz, S. C. J. Org. Chem. 1976, 41, 10. (c) Komatsu, M.; Suehiro, I.; Horiguchi, Y.; Kuwajima, I. Synlett 1991, 771. (d) Saigo, K.; Shimada, S.; Shibasaki, T.; Hasegawa, M. Chem. Lett. 1990, 1093. (e) Marino, J. P.; Laborde, E. J. Am. Chem. Soc. 1985, 107, 734. (f) Beal, R. B.; Dombroski, M. A.; Snider, B. B. J. Org. Chem. 1986, 51, 4391. (g) Graziano, M. L.; Chiosi, S. J. Chem. Res. S. 1989, 44.

(66) (a) Harrington, P.; Kerr, M. A. Tetrahedron Lett. 1997, 38 , 5949. (b) Kerr, M. A.; Keddy, R. G. Tetrahedron Lett. 1999, 40, 5671. (c) England, D. B.; Kuss, T. D. O.; Keddy, R. G.; Kerr, M. A. J. Org. Chem. 2001, 66, 4704. (d) England, D. B.; Woo, T. K.; Kerr, M. A. Can. J. Chem. 2002, 80, 992. (e) Venkatesh, C.; Singh, P. P.; Ila, H.; Junjappa, H. Eur. J. Org. Chem. 2006, 5378.

(67) (a) Bajtos, B.; Yu, M.; Zhao, H. D.; Pagenkopf, B. L. J. Am. Chem. Soc. 2007, 129, 9634. (b) Chagarovskiy, A. O.; Budynina, E. M.; Ivanova, O. A.; Grishin, Y. K.; Trushkov, I. V.; Verteletskii, P. V. Tetrahedron 2009, 65, 5385.
(68) (a) Sugita, Y.; Yamadoi, S.; Hosoya, H.; Yokoe, I. Chem. Pharm. Bull. 2001, 49, 657. (b) Yadav, V. K.; Sriramurthy, V. Org. Lett. 2004, 6, 4495.

(69) (a) Takasu, K.; Nagao, S.; Ihara, M. Adv. Synth. Catal. 2006, 348, 2376. (b) Fang, J.; Ren, J.; Wang, Z. W. Tetrahedron Lett. 2008, 49, 6659 .

(70) (a) Graziano, M. L.; Iesce, M. R.; Cermola, F.; Cimminiello, G. J. Chem. Res. S. 1992, 4. (b) Yadav, V. K.; Sriramurthy, V. Angew. Chem., Int. Ed. 2004, 43, 2669.

(71) Qi, X. B.; Ready, J. M. Angew. Chem., Int. Ed. 2008, 47, 7068.

(72) (a) Liu, L.; Montgomery, J. J. Am. Chem. Soc. 2006, 128, 5348. (b) Liu, L.; Montgomery, J. Org. Lett. 2007, 9, 3885.

(73) (a) Shimada, S.; Hashimoto, Y.; Sudo, A.; Hasegawa, M.; Saigo, K. J. Org. Chem. 1992, 57, 7126. (b) Shimada, S.; Hashimoto, Y.; Nagashima, T.; Hasegawa, M.; Saigo, K. Tetrahedron 1993, 49, 1589. (c) Shimada, S.; Hashimoto, Y.; Saigo, K. J. Org. Chem. 1993, 58, 5226. (d) Sugita, Y.; Kawai, K.; Yokoe, I. Heterocycles 2000, 53, 657. (e) Sugita, Y.; Kawai, K.; Yokoe, I. Heterocycles 2001, 55, 135. (f) Han, Z.; Uehira, S.; Tsuritani, T.; Shinokubo, H.; Oshima, K. Tetrahedron 2001, 57, 987.

(74) Gupta, A.; Yadav, V. K. Tetrahedron Lett. 2006, 47, 8043.

(75) (a) Pohlhaus, P. D.; Johnson, J. S. J. Org. Chem. 2005, 70, 1057. (b) Pohlhaus, P. D.; Johnson, J. S. J. Am. Chem. Soc. 2005, 127, 16014. (c) Pohlhaus, P. D.; Sanders, S. D.; Parsons, A. T.; Li, W.; Johnson, J. S. J. Am. Chem. Soc. 2008, $130,8642$.

(76) (a) Yankee, E. W.; Cram, D. J. J. Am. Chem. Soc. 1970, 92, 6328. (b) Sliwinska, A.; Czardybon, W.; Warkentin, J. Org. Lett. 2007, 9, 695. (c) Zhang, J. S.; Shen, W.; Li, M. Eur. J. Org. Chem. 2007, 4855.

(77) Parsons, A. T.; Johnson, J. S. J. Am. Chem. Soc. 2009, 131, 3122.

(78) Parsons, A. T.; Campbell, M. J.; Johnson, J. S. Org. Lett. 2008, 10, 2541.

(79) Alper, P. B.; Meyers, C.; Lerchner, A.; Siegel, D. R.; Carreira, E. M. Angew. Chem., Int. Ed. 1999, 38, 3186.

(80) (a) Bertozzi, F.; Gustafsson, M.; Olsson, R. Org. Lett. 2002, 4, 3147.

(81) (a) Huang, W. W.; O'Donnell, M. M.; Bi, G.; Liu, J. F.; Yu, L. B.; Baldino, C. M.; Bell, A. S.; Underwood, T. J. Tetrahedron Lett. 2004, 45, 8511. (b) Huang, W. W.; Chin, J.; Karpinski, L.; Gustafson, G.; Baldino, C. M.; Yu, L. B. Tetrahedron Lett. 2006, 47, 4911. (c) Carson, C. A.; Kerr, M. A. J. Org. Chem. 2005, 70, 8242. (d) Kang, Y. B.; Tang, Y.; Sun, X. L. Org. Biomol. Chem. 2006, 4, 299. (e) Christie, S. D. R.; Davoile, R. J.; Jones, R. C. F. Org. Biomol. Chem. 2006, 4, 2683. (f) Noda, H.; Wiedemann, S. H.; Matsunaga, S.; Shibasaki, M. Chem. Lett. 2008, 37, 1180.

(82) Jackson, S. K.; Karadeolian, A.; Driega, A. B.; Kerr, M. A. J. Am. Chem. Soc. 2008, 130, 4196.

(83) (a) Lautens, M.; Han, W. S. J. Am. Chem. Soc. 2002, 124, 6312. (b) Scott, M. E.; Han, W.; Lautens, M. Org. Lett. 2004, 6, 3309. (c) Taillier, C.; Bethuel, Y.; Lautens, M. Tetrahedron 2007, 63, 8469. (d) Taillier, C.; Lautens, M. Org. Lett. 2007, 9, 591. (e) Scott, M. E.; Lautens, M. J. Org. Chem. 2008, 73, 8154.

(84) (a) Yu, M.; Pagenkopf, B. L. J. Am. Chem. Soc. 2003, 125, 8122. (b) Yu, M.; Pagenkopf, B. L. Org. Lett. 2003, 5, 5099. (c) Yu, M.; Pantos, G. D.; Sessler, J. L.; Pagenkopf, B. L. Org. Lett. 2004, 6, 1057.

(85) Morra, N. A.; Morales, C. L.; Bajtos, B.; Wang, X.; Jang, H.; Wang, J.; Yu, M.; Pagenkopf, B. L. Adv. Synth. Catal. 2006, 348, 2385.

(86) Tanaka, M.; Ubukata, M.; Matsuo, T.; Yasue, K.; Matsumoto, K.; Kajimoto, Y.; Ogo, T.; Inaba, T. Org. Lett. 2007, 9, 3331 . 
(87) (a) Bruckner, C.; Reissig, H. U. Angew. Chem., Int. Ed. Engl. 1985, 24, 588. (b) Graziano, M. L.; Iesce, M. R. $J$ Chem. Res. S. 1987, 362. (c) Graziano, M. L.; Cimminiello, G. J. Chem. Res. S. 1989, 42. (d) Graziano, M. L.; Iesce, M. R.; Cermola, F. J. Chem. Res. S. 1996, 82. (e) Korotkov, V. S.; Larionov, O. V.; Hoftneister, A.; Magull, J.; De Meijere, A. J. Org. Chem. 2007, 72, 7504. (f) Cermola, F.; Di Gioia, L.; Graziano, M. L.; Iesce, M. R. J. Chem. Res. S. 2005, 677. (g) Korotkov, V. S.; Larionov, O. V.; De Meijere, A. Synthesis 2006, 3542.

(88) Venkatesh, C.; Ila, H.; Junjappa, H.; Mathur, S.; Hucht, V. J. Org. Chem. 2002, 67, 9477.

(89) (a) Young, I. S.; Kerr, M. A. Angew. Chem., Int. Ed. 2003, 42, 3023. (b) Young, I. S.; Kerr, M. A. Org. Lett. 2004, 6, 139. (c) Ganton, M. D.; Kerr, M. A. J. Org. Chem. 2004, 69, 8554. (d) Wanapun, D.; Van Gorp, K. A.; Mosey, N. J.; Kerr, M. A.; Woo, T. K. Can. J. Chem. 2005, 83, 1752. (e) Lebold, T. P.; Carson, C. A.; Kerr, M. A. Synlett 2006, 364. (f) Karadeolian, A.; Kerr, M. A. J. Org. Chem. 2007, 72, 10251. (g) Sapeta, K.; Kerr, M. A. J. Org. Chem. 2007, 72, 8597. (h) Carson, C. A.; Young, I. S.; Kerr, M. A. Synthesis 2008, 485. For a review on the recent use of nitrones in cycloaddition and other reactions, see: (i) Cardona, F.; Goti, A. Angew. Chem., Int. Ed. 2005, 44, 7832.

(90) Sibi, M. P.; Ma, Z. H.; Jasperse, C. P. J. Am. Chem. Soc. 2005, 127, 5764.

(91) Kang, Y. B.; Sun, X. L.; Tang, Y. Angew. Chem., Int. Ed. 2007, 46, 3918.

(92) Hu, B.; Zhu, J. L.; Xing, S. Y.; Fang, J.; Du, D.; Wang, Z. W. Chem. Eur. J. 2009, 15, 324.

(93) Ding, Q. P.; Wang, Z. Y.; Wu, J. Tetrahedron Lett. 2009, 50, 198.

(94) Perreault, C.; Goudreau, S. R.; Zimmer, L. E.; Charette, A. B. Org. Lett. 2008, 10, 689.

(95) Sapeta, K.; Kerr, M. A. Org. Lett. 2009, 11, 2081.

(96) (a) Ivanova, O. A.; Budynina, E. M.; Grishin, Y. K.; Trushkov, I. V.; Verteletskii, P. V. Angew. Chem., Int. Ed. 2008, 47, 1107. (b) Ivanova, O. A.; Budynina, E. M.; Grishin, Y. K.; Trushkov, I. V.; Verteletskii, P. V. Eur. J. Org. Chem. 2008, 5329.

(97) Snider, B. B.; Ahn, Y.; O'Hare, S. M. Org. Lett. 2001, 3, 4217.

(98) (a) Nosse, B.; Chhor, R. B.; Jeong, W. B.; Bohm, C.; Reiser, O. 2003, 5, 941. (b) Kalidindi, S.; Jeong, W. B.; Schall, A.; Bandichhor, R.; Nosse, B.; Reiser, O. Angew. Chem., Int. Ed. 2007, 46, 6361.

(99) (a) Fischer, C.; Meyers, C.; Carreira, E. M. Helv. Chim. Acta 2000, 83, 1175. (b) Lerchner, A.; Carreira, E. M. J. Am. Chem. Soc. 2002, 124, 14826. (c) Lerchner, A.; Carreira, E. M. Chem. Eur. J. 2006, 12, 8209. (d) Meyers, C.; Carreira, E. M. Angew. Chem., Int. Ed. 2003, 42, 694. (f) Marti, C.; Carreira, E. M. J. Am. Chem. Soc. 2005, 127, 11505. (g) Marti, C.; Carreira, E. M. Eur. J. Org. Chem. 2003, 2209.

(100) Leduc, A. B.; Kerr, M. A. Angew. Chem., Int. Ed. 2008, 47, 7945.

(101) Carson, C. A.; Kerr, M. A. Org. Lett. 2009, 11, 777.

(102) (a) Morales, C. L.; Pagenkopf, B. L. Org. Lett. 2008, 10, 157. (b) Bajtos, B.; Pagenkopf, B. L. Eur. J. Org. Chem. 2009, 1072.

(103) (a) Carson, C. A.; Kerr, M. A. Angew. Chem., Int. Ed. 2006, 45, 6560. (b) Young, I. S.; Williams, J. L.; Kerr, M. A. Org. Lett. 2005, 7, 953. (c) Young, I. S.; Kerr, M. A. J. Am. Chem. Soc. 2007, 129, 1465. (d) Johansen, M. B.; Kerr, M. A. Org. Lett. 2008, 10, 3497. 


\section{Cyclization and Cycloaddition Reactions of Cyclopropyl Carbonyls and Imines}<smiles>[R]C(=O)C1CC([R])C(C([R])=O)C1[R1]</smiles>

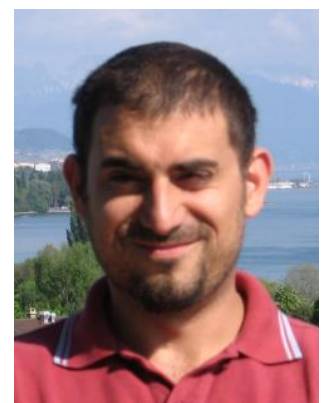

Filippo De Simone was born in Rome (Italy) in 1980. He studied at the Faculty of Pharmacy at the University of Rome 1 "La Sapienza" where he obtained his diploma in Pharmaceutical Chemistry in 2007. During his studies he was awarded two international fellowships that allowed him to spend 24 months in the University "Jules Verne" (France) where he worked on the synthesis of biologically active compounds. He is currently in the second year of his $\mathrm{PhD}$ studies in the Ecole Polytechnique Fédérale de Lausanne (Switzerland) working on the catalytic cyclization of polycyclic scaffolds under the direction of Prof. Jérôme Waser.

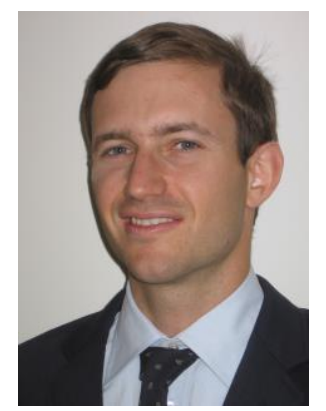

Jérôme Waser was born in Sierre, Valais, Switzerland in 1977. He studied chemistry at ETH Zurich and obtained his Diploma in 2001. In 2002, he started his PhD studies at ETH Zurich with Prof. Erick M. Carreira, working on the development of metal-catalyzed amination reactions of olefins. In 2006, he joined Prof. Barry M. Trost at Stanford University and accomplished the total synthesis of Pseudolaric Acid B, a diterpene natural product. Since October 2007, he is working as tenure-track assistant professor at EPF Lausanne, focusing on the development and application of catalytic methods for the synthesis of bioactive compounds. 